This document is confidential and is proprietary to the American Chemical Society and its authors. Do not copy or disclose without written permission. If you have received this item in error, notify the sender and delete all copies.

\title{
LIGHT-RESPONSIVE SELF-ASSEMBLED MATERIALS BY SUPRAMOLECULAR POST-FUNCTIONALIZATION VIA HYDROGEN BONDING OF AMPHIPHILIC BLOCK COPOLYMERS
}

\begin{tabular}{|r|l|}
\hline Journal: & Macromolecules \\
\hline Manuscript ID & ma-2016-01112s.R1 \\
\hline Manuscript Type: & Article \\
\hline Date Submitted by the Author: & n/a \\
\hline Complete List of Authors: & $\begin{array}{l}\text { Concellon, Alberto; Universidad de Zaragoza, } \\
\text { Blasco, Eva; Karlsruhe Institut of Technology, } \\
\text { Martinez-Felipe, Alfonso; University of Aberdeen, School of Engineering } \\
\text { Martinez, Juan Carlos; CELLS-ALBA } \\
\text { Sics, Igors; CELLS-ALBA } \\
\text { Ezquerra, Tiberio; CSIC, Instituto de Estructura de la Materia } \\
\text { Nogales, Aurora; Inst.de Estructura de la Materia,C.S.I.C, Fisica } \\
\text { Macromolecular } \\
\text { Piñol, Milagros; Universidad de Zaragoza, Departamento de Química } \\
\text { Orgánica } \\
\text { Oriol, Luis; Universidad de Zaragoza-CSIC, Quimica Organica }\end{array}$ \\
\hline
\end{tabular}

\section{SCHOLARONE"}

Manuscripts 


\title{
LIGHT-RESPONSIVE SELF-ASSEMBLED
}

\author{
MATERIALS BY SUPRAMOLECULAR POST-
}

\author{
FUNCTIONALIZATION VIA HYDROGEN
}

\section{BONDING OF AMPHIPHILIC BLOCK}

\section{COPOLYMERS}

Alberto Concellón, ${ }^{\dagger}$ Eva Blasco, ${ }^{\ddagger}$ Alfonso Martínez-Felipe, ${ }^{\S}$ Juan Carlos Martínez, ${ }^{\ddagger}$ Igor Šics, ${ }^{\neq}$

Tiberio A. Ezquerra, ${ }^{\|}$Aurora Nogales, $\|, *$ Milagros Piñol ${ }^{\dagger, *}$ and Luis Oriol, *

${ }^{\dagger}$ Departamento de Química Orgánica, Instituto de Ciencia de Materiales de Aragón (ICMA)-

Facultad de Ciencias, Universidad de Zaragoza-CSIC, 50009, Zaragoza, Spain

* Preparative Macromolecular Chemistry, Institut für Technische Chemie und Polymerchemie, Karlsruhe Institute of Technology (KIT), Engesserstr. 18, 76128 Karlsruhe, Germany

${ }^{\S}$ Chemical and Materials Engineering Group, School of Engineering, University of Aberdeen. King's College, Aberdeen AB24 3UE, UK.

${ }^{\ddagger}$ Cells-Alba, Carretera BP 1413, 08290 Cerdanyola del Vallès, Barcelona, Spain

" Instituto de Estructura de la Materia, IEM-CSIC, C/Serrano 121, 28006 Madrid, Spain

* Authors for correspondence: aurora.nogales@csic.es, mpinol@unizar.es, loriol@unizar.es 


\begin{abstract}
A new class of light-responsive supramolecular amphiphilic block copolymers (BCs) based on the association through multiple H-bonding between 4-isobutyloxyazobenzene motifs and 2,6diacylaminepyridine units is reported. Block copolymers containing 2,6-diacylaminopyridine side units, as hydrophobic block, and poly(ethylene glycol), as a hydrophilic segment, were functionalized with either a carboxylic acid azodendron, via double H-bonding, or a thymine azobenzene, via triple H-bonding. The structural and thermal characterization of these supramolecular azo-copolymers in bulk and solution is presented. The work emphasizes the selfassembly of these supramolecular polymers in water and the study of their UV-light responsive properties by UV-vis spectroscopy, dynamic light scattering (DLS), transmission electron microscopy (TEM), and synchrotron small-angle X-ray (SAXS). The present noncovalent postpolymerization functionalization strategy has provided stable self-assemblies in water with light responsive properties that can be used to load and trigger the delivery of small fluorescent molecules.
\end{abstract}




\section{INTRODUCTION}

The design of efficient drug delivery vehicles remains a true challenge in polymer and materials science. A variety of polymeric nanocarriers have been described in recent years based on the ability of amphiphilic block copolymers (BCs) to spontaneously generate assemblies in water, such as micelles or vesicles, whose size and morphology are highly dependent on the composition, molecular geometry and relative block lengths of the BCs. ${ }^{1-5}$ The incorporation of $\mathrm{pH}-$, temperature- or light-responsive moieties into these amphiphilic BCs makes them potential candidates as systems for controlled release. ${ }^{6-8}$ The use of light as an external stimulus is particularly advantageous as provides with temporal and spatial control in the material response. $^{9-12}$ Among other photocromic moieties, azobenzene presents rapid, reversible, and high quantum yield photoisomerization, and is undoubtedly the most widely investigated group in the design of light-responsive systems based on amphiphilic BCs. ${ }^{13}$

In previous contributions, we have reported on photoresponsive vesicles based on amphiphilic linear-dendritic block copolymers, LDBCs, with hydrophilic/hydrophobic weight ratios of approx. 20/80, and bearing 4-cyanoazobenzene moieties. ${ }^{14}$ Theoretical simulations on these systems predicted the disruption of macromolecular aggregates by photoisomerization that could ultimately trigger the release of encapsulated molecules. ${ }^{15}$ Alternatively, we investigated the use of 4-alkoxyazobenzene photoresponsive units that facilitate the disruption of the assemblies under UV irradiation. ${ }^{16}$ The resulting vesicles were loaded with both hydrophobic and hydrophilic fluorescent probes to demonstrate that the distortion of the bilayer membrane under low intensity UV irradiation increases its permeability to the encapsulated molecules. ${ }^{17,18}$ Those light-responsive vesicles were based on covalent polymeric systems, and the time-consuming synthetic procedures involved reduce their practical feasibility in controlled drug release. ${ }^{19,20}$ 
The introduction of supramolecular polymers by Kato and Fréchet, ${ }^{21}$ and Lehn and coworkers, ${ }^{22}$ broadened the playground for polymer chemists, which is no longer restricted to macromolecular species based on the repetition of monomeric units governed by covalent bonding. Supramolecular polymeric materials combine many of the attractive features of conventional covalent polymers with the properties resulting from the reversibility of noncovalent interactions. ${ }^{23-26}$ In this context, several works have reported on the preparation and application of noncovalent azobenzene-containing polymers. Ionic interactions were used by Bazuin and coworkers for grafting azobenzene derivatives to methylated poly(4-vinylpyridine), yielding liquid crystalline polyelectrolytes ${ }^{27}$, and by Marcos and coworkers for the preparation of azobenzene containing poly(propyleneimine) codendrimers by simple acid-base titration. ${ }^{28-30}$

Alternatively, hydrogen bonding combines ease of preparation with high specificity and directionality between components. Priimagi and coworkers pioneered the research on hydrogen bonded supramolecular side chain azopolymers by complexing poly(4-vinylpyridine) with a variety of azobenzene molecules. ${ }^{31-35}$ This strategy can be extended to build supramolecular block copolymers (BCs) yielding materials with multiple-level hierarchical self-assembly. Thus, we investigated a series of photo-responsive supramolecular polymers prepared by mixing carboxylic terminated promesogenic azobenzene derivatives with commercially available poly(styrene)-block-poly(4-vinylpyridine) copolymers. $^{36,37}$ In these systems, the azo chromophore was linked to the polymer via hydrogen bonding through molecular recognition between the carboxylic groups (H-donor) and the pyridine rings ( $\mathrm{H}$-acceptor). However, even though the materials exhibited good photoresponsive properties, high levels of complexation led to some degree of macroscopic segregation between the components (i.e., for $100 \%$ substitution of the pyridine pendant units). In an attempt to overcome such limitation and prepare 
quantitative complexated supramolecular BCs, we have used functional groups capable of forming multiple hydrogen bonds. With that aim, we have reported on diblock copolymers having a poly(methyl methacrylate) block bearing 2,6-diacylaminopyridine pendant moieties, which were fully complexated with 4-cyanoazobenzene derivatives to obtain homogeneous materials. $^{38}$

Recently, we have described the preparation and self-assembly of analogous amphiphilic BCs and described their potential as polymeric-based nanocarriers for hydrophobic drugs. ${ }^{39}$ These amphiphilic BCs contained a polymethacrylate block bearing pendant 2,6-diacylaminopyridine units (PDAP) and a poly(ethylene glycol) block (PEG) of two different average molar masses, 2000 and $10000 \mathrm{~g} \mathrm{~mol}^{-1}$ (PEG $\mathbf{2}-\boldsymbol{b}$-PDAP and $\mathbf{P E G}_{\mathbf{1 0}} \mathbf{- b}$-PDAP, respectively) (Figure 1a). Polymeric micelles were prepared from these block copolymers, and were then used to load camphtothecin, an effective antiviral against Hepatitis $\mathrm{C}$ virus (HCV), simply by physical diffusion. The cytotoxicity and antiviral activity against HVC of the camphtothecin-loaded polymeric micelles were tested and the feasibility of these polymers as drug delivery systems demonstrated.

In the search of highly functionalized ligh-responsive nanocarriers, and encouraged by the ability of the 2,6-diacylaminopyridine moiety to form multiple hydrogen bonds, here we report on new amphiphilic supramolecular BCs obtained by complexation of PEG $\mathbf{P}-\boldsymbol{b}$-PDAP and $\mathbf{P E G}_{\mathbf{1 0}} \mathbf{- b}$-PDAP with two 4-isobutyloxyazo derivatives, namely $\mathbf{A A Z O _ { i }}$ and $\mathbf{t A Z O} \mathbf{O}_{\mathbf{i}}$ dAZO $\mathbf{A}$ is a dendron that contains three peripheral 4-isobutyloxyazobenzene moieties and a carboxylic acid focal point, while $\mathbf{t A Z O}$ i contains a thymine head linked to one 4-isobutyloxyazobenzene unit (Figure 1b). It is envisaged that the 2,6-diacylaminopyridine pendant groups will form either two $\left(\mathbf{d A Z O} \mathbf{O}_{\mathbf{i}}\right)$ or three $\left(\mathbf{t} \mathbf{A Z O} \mathbf{O}_{\mathbf{i}}\right)$ hydrogen bonds (Figure 1c) with the azobenzene derivatives. 
The present work describes the preparation, characterization and thermal properties of these new light-responsive, amphiphilic supramolecular polymers. Since these materials are targeted as controlled release systems, we also present a detailed characterization of the corresponding assemblies in water and their light-responsive behavior by transmission electron microscopy (TEM), dynamic light scattering (DLS) and synchrotron small-angle X-ray (SAXS), as well as encapsulation-release studies using fluorescent probes.

a)

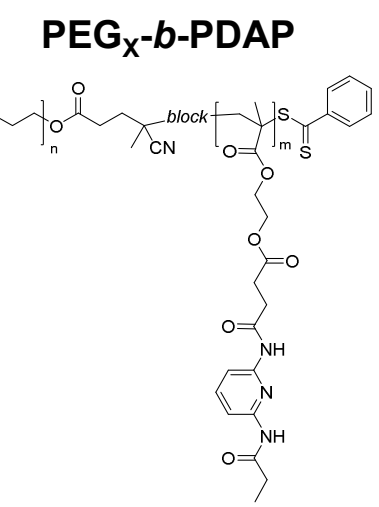

c)

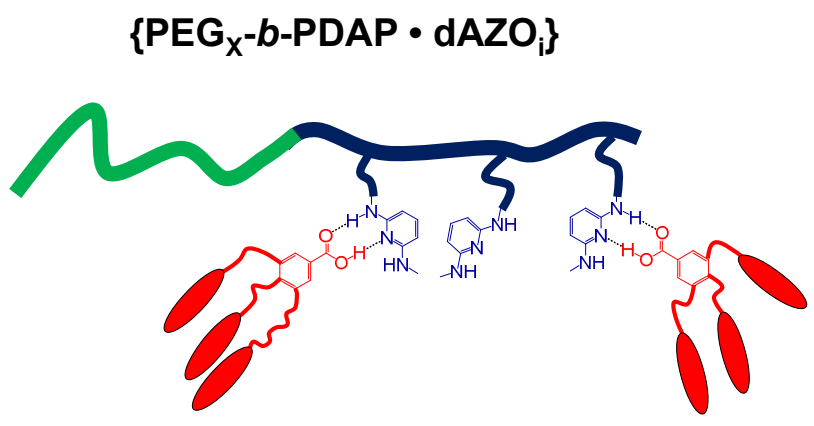

b)
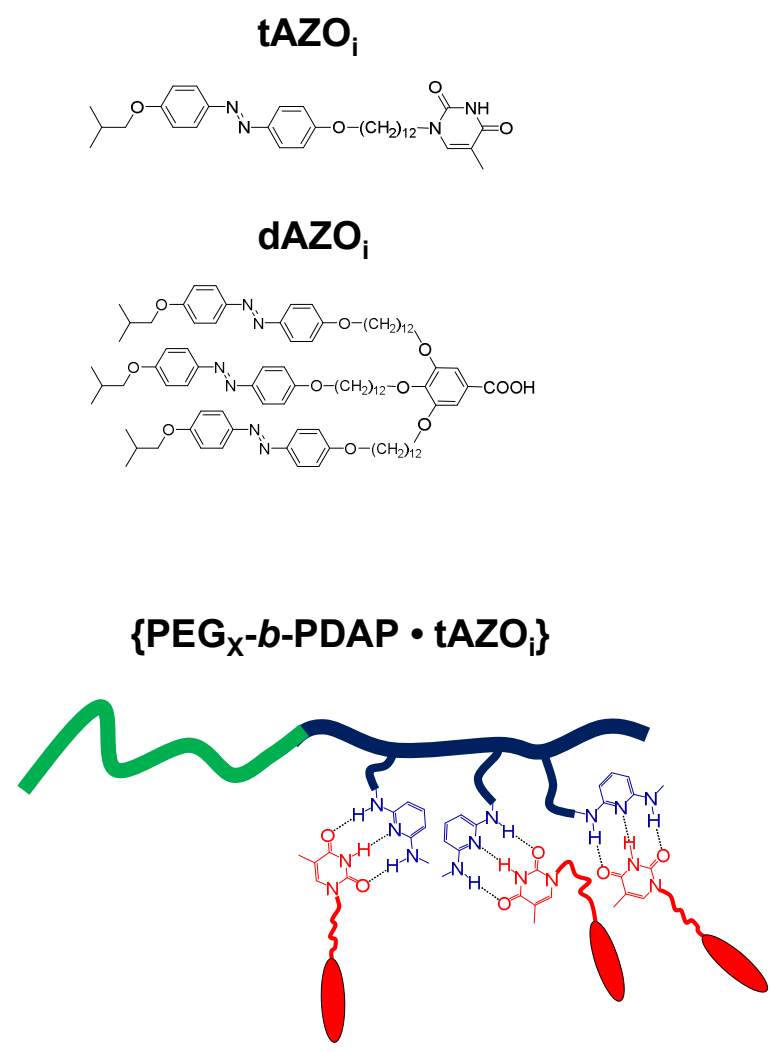

Figure 1. Chemical structure of (a) $\mathbf{P E G}_{\mathbf{X}}-\boldsymbol{b}$-PDAP block polymers, (b) $\mathbf{t A Z O}_{\mathbf{i}}$ and $\mathbf{d A Z O}_{\mathbf{i}}$ compounds and, schematic representation of (c) azobenzene-containing supramolecular BCs.

EXPERIMENTAL SECTION 
Materials. The preparation of the PDAP homopolymer and $\mathbf{P E G}_{\mathbf{X}}-\boldsymbol{b}$-PDAP amphiphilic block copolymers have been reported elsewhere, ${ }^{38,} 39$ and details of the synthesis and characterization of $\mathbf{A} \mathbf{A Z O} \mathbf{O}_{\mathbf{i}}$ and $\mathbf{d A Z O} \mathbf{O}_{\mathbf{i}}$ can be found in the Supporting Information.

Preparation of supramolecular polymers. Required amounts of the polymer and the corresponding azocompounds were weighted and dissolved in THF followed by slow evaporation under stirring at room temperature. The supramolecular polymers were dried under vacuum at $40^{\circ} \mathrm{C}$ for at least 2 days. For characterization in the bulk, polymers were first heated up to $175^{\circ} \mathrm{C}$ for $5 \mathrm{~min}$ and rapidly quenched to room temperature to have a controlled thermal history.

Preparation of self-assemblies in water. Milli-Q water was gradually added to a solution of $5 \mathrm{mg} \mathrm{mL}^{-1}$ of the corresponding BC in tetrahydrofuran, THF, and the self-assembly process was followed by measuring the loss of intensity of transmitted light at $650 \mathrm{~nm}$ due to scattering (turbidimetry) as a function of the water content. At a critical water value, a sudden increase of turbidity occurs coinciding with the onset of polymer self-assembly. When a constant value of turbidity was reached, the mixture was dialyzed against water to remove THF using a Spectra/Por ${ }^{\circledR}$ dialysis membrane (MWCO 1000) for 4 days. Water suspensions of the polymeric self-assemblies were obtained with concentrations around $1.7 \mathrm{mg} \mathrm{mL}^{-1}$.

\section{Determination of the Critical Agregation Concentration (CAC). Critical aggregation} concentration (CAC) was determined by fluorescence spectroscopy using Nile Red as the probe as follows. $119 \mu \mathrm{L}$ of a solution of Nile Red in dichloromethane $\left(5 \times 10^{-6} \mathrm{M}\right)$ was added into a series of flasks and then the solvent evaporated. Afterwards, water suspensions of the selfassemblies, prepared by diluting the former $1.7 \mathrm{mg} \mathrm{mL}^{-1}$ suspension, were added to each flask 
with concentrations ranging from $1.0 \times 10^{-4}$ to $1.0 \mathrm{mg} \mathrm{mL}^{-1}$. In each flask a final concentration of $1.0 \times 10^{-6} \mathrm{M}$ of Nile Red was reached and the resulting suspensions were stirred overnight at room temperature to reach equilibrium before fluorescence was measured. The emission spectra of Nile Red were registered from 560 to $700 \mathrm{~nm}$ while exciting at $550 \mathrm{~nm}$.

Loading of Rhodamine B into the vesicle. Loaded vesicles were formed following the same procedure described for the preparation of self-assemblies but using a solution of Rhodamine B in Milli-Q water. The BC was dissolved in THF and the aqueous solution of Rhodamine B was gradually added. The charge ratio was 1:5 mol copolymer/mol dye. Self-assembly was monitored by turbidimetry until an almost constant value was reached. Finally, the mixture was dialyzed against water to remove THF and non-encapsulated Rhodamine B, and the absorbance of the resulting solution was measured. The absorption values were compared to a calibration curve of Rhodamine B, previously obtained, in order to determine the quantity of nonencapsulated dye molecules and therefore the number of molecules encapsulated in the vesicle.

Irradiation experiments. The water dispersions of the self-assemblies were irradiated with a compact low-pressure fluorescent lamp Philips PL-S 9W emitting between 350 and $400 \mathrm{~nm}$. The samples were placed at a distance of $10 \mathrm{~cm}$ from the light source in quartz cuvettes at room temperature. After irradiation, the water suspensions were kept in the dark.

Techniques. Fourier transform infrared spectroscopy (FTIR) was applied using a Bruker Vertex 70 FT-IR spectrophotometer and $\mathrm{KBr}$ pellets or films deposited by casting over $\mathrm{BaF}_{2}$. Solution NMR experiments were carried out on Bruker Avance spectrometers operating at 400 or $300 \mathrm{MHz}$ for ${ }^{1} \mathrm{H}$, and 100 or $75 \mathrm{MHz}$ for ${ }^{13} \mathrm{C}$, using standard pulse sequences. Chemical shifts are given in ppm relative to TMS and the solvent residual peak was used as internal reference. 
Thermogravimetric analysis (TGA) were performed using a Q5000IR module from TA instruments at a heating rate of $10{ }^{\circ} \mathrm{C} \mathrm{min}^{-1}$ under a nitrogen atmosphere. Thermal transitions were determined by differential scanning calorimetry (DSC) using a Q2000 calorimeter from TA instruments on powdered samples $(2-5 \mathrm{mg})$ sealed in aluminum pans. Glass transition temperatures $\left(T_{\mathrm{g}}\right)$ were determined at the half height of the baseline jump, and first order transition temperatures were read at the maximum of the corresponding peak for the polymers and at the onset for low molar mass compounds. The homogeneity of the samples was inspected by polarizing optical microscopy (POM) using an Olympus BH-2 polarizing microscope fitted with a Linkam THMS600 hot stage. UV-Vis absorption spectra were recorded in an ATIUnicam UV4-200 spectrophotometer. Fluorescence measurements were performed using a Perkin Elmer LS 50B fluorescence spectrophotometer. Dynamic light scattering (DLS) measurements were carried out in a Malvern Instrument Nano ZS using a He-Ne laser with a $633 \mathrm{~nm}$ wavelength, a detector angle of $173^{\circ}$ at $25^{\circ} \mathrm{C}$ using a $\mathrm{He}-\mathrm{Ne}$ laser with a $633 \mathrm{~nm}$ wavelength. The self-assemblies concentrations were $0.075 \mathrm{mg} \mathrm{mL}^{-1}$ and size measurements were performed at least three times on each sample to ensure reproducibility.

\section{Transmission electron microscopy (TEM) and cryoscopic transmission electron microscopy (Cryo-TEM). The morphology of the block copolymer vesicles was studied by} transmission electron microscopy (TEM) using JEOL-2000 FXIII and TECNAI G 20 (FEI COMPANY) electron microscopes operating at $200 \mathrm{kV}$. For the preparation of TEM samples, 5 $\mu \mathrm{L}$ of a $0.5 \mathrm{mg} \mathrm{mL}^{-1}$ water dispersions of the self-assemblies were deposited onto carbon-coated copper grid, and the water was then removed by capillarity using filter paper. The samples were stained with uranyl acetate and the grid was left to dry overnight under vacuum. The $0.5 \mathrm{mg} \mathrm{mL}^{-}$

${ }^{1}$ suspension was prepared by diluting the former $1.7 \mathrm{mg} \mathrm{mL}^{-1}$ suspension with Milli-Q water. 
Cryo-TEM experiments were performed using a JEM-2011 electron microscope, and samples for inspection were prepared by casting $5 \mu \mathrm{L}$ of a $1.7 \mathrm{mg} \mathrm{mL}^{-1}$ water dispersion of self-assemblies on a suitable grid and then quenched in liquid ethane.

Confocal Microscopy. Samples were observed with an Olympus FV10i confocal scanning microscope. Images were collected using a $60 \times$ oil immersion lens (lens specification, Plan SAPO $60 \times \mathrm{O}$, NA 1.35 ), a line average of 8 and a format of $1024 \times 1024$ pixels. The confocal pinhole was 1 Airy unit. Samples preparation consisted on casting $5 \mu \mathrm{L}$ of a $1.7 \mathrm{mg} \mathrm{mL}^{-1}$ water dispersions of self-assemblies with encapsulated Rhodamine B on a glass slide, followed by covering with a slip on the top. The edges were sealed to avoid solvent evaporation during measurement.

Small Angle X-Ray Scattering (SAXS). X-ray scattering techniques provide information about the structure and molecular conformations at different length scales. SAXS is particularly suitable when studying supramolecular organization in the length scale of tens of nanometers, ${ }^{40}$ and in combination with synchrotron radiation allows monitoring changes in real time in both conformation and structure. ${ }^{41}$ Experiments were performed at beamline BL11-NCD (ALBA, Spain) using a wavelength of $0.1 \mathrm{~nm}$. The SAXS detector (ADSC, Quantum 210r CCD, pixel size $102 \mu \mathrm{m}$ ) was located at $6430 \mathrm{~mm}$ distance from the sample position. Experiments under UV irradiation were performed at room temperature, and SAXS patterns were collected while the sample was irradiated with a UV lamp (Phillips PL-S 9W) placed at a distance of $10 \mathrm{~cm}$. The angular ( $q$-axis) was calibrated using standard samples of Silver Behenate.

\section{RESULTS AND DISCUSSION}


Preparation and characterization of supramolecular polymers. The supramolecular block copolymers were prepared by dissolving corresponding amounts of the parent BCs (PEG $\mathbf{X}-\boldsymbol{b}$ PDAP) and the azocompounds $\left(\mathbf{d A Z O} \mathbf{A}_{\mathbf{i}}\right.$ or $\left.\mathbf{t A Z O} \mathbf{Z}_{\mathbf{i}}\right)$ in THF, followed by slow evaporation of the solvent under continuous stirring at room temperature. According to our previous results on covalent LDBCs, the degree of complexation (number of azo molecules per 2,6diacylaminopyridine repeating unit) was adjusted to achieve hydrophilic/hydrophobic weight ratios of approx. 20:80 in order to predominantly yield vesicles. ${ }^{14}$ Therefore, a degree of complexation of 1 was used with $\mathbf{t A Z O}$, while 0.30 was used with $\mathbf{d A Z O} \mathbf{O}_{\mathbf{i}}$ (see Table 1). For comparative purposes, fully complexed supramolecular polymers (degree of complexation $=1$ ) of the homopolymer $\mathbf{P D A P}^{38}$ with either $\mathbf{A A Z O}$ or $\mathbf{A} \mathbf{A Z O} \mathbf{O}_{\mathbf{i}}$ were also prepared, namely $\left\{P D A P \bullet d A Z O_{i}\right\}$ and $\{$ PDAP•tAZO $\}$.

The ${ }^{1} \mathrm{H}$ NMR spectra of the supramolecular $\mathrm{BCs}$ in $\mathrm{CDCl}_{3}$ proved the formation of hydrogen bonded complexes, assuming that there is a rapid equilibrium between the complex and its components. In general, proton signals involved in the hydrogen bonds, as well as those that are close to the complexing groups, experienced correlated changes in their chemical shifts. As a representative example, the ${ }^{1} \mathrm{H}$ NMR spectra of the $\left\{\mathbf{P E G}_{\mathbf{2}}-\boldsymbol{b}-\mathbf{P D A P} \bullet \mathbf{A Z Z O} \mathbf{O}_{\mathrm{i}}\right\}$ and $\left\{\mathbf{P E G}_{\mathbf{2}}-\boldsymbol{b}\right.$ PDAP•dAZO $\left.{ }_{i}\right\}$ supramolecular polymers are shown in Figure 2, along with those of their respective components.

The formation of hydrogen bonds between complementary $\mathbf{T A Z O}_{\mathbf{i}}$ and 2,6diacylaminopyridine units in $\left\{\mathbf{P E G}_{\mathbf{2}}-\boldsymbol{b}\right.$-PDAP•tAZO $\left.\mathbf{O}_{\mathrm{i}}\right\}$ was assessed by the simultaneous downfield shifts of the $\mathrm{N}-\mathrm{H}$ signals of the PDAP block $\left(H_{A}\right.$, from 8.45 to $\left.9.23 \mathrm{ppm}\right)$ and the thymine unit ( $H_{B}$,from 8.25 to $\left.9.71 \mathrm{ppm}\right)$. In the case of supramolecular BCs containing $\mathbf{d A Z O}_{\mathbf{i}}$, the 2,6-diacylaminopyridine $\mathrm{N}-\mathrm{H}$ protons $\left(H_{A}\right)$ experienced slight downfield 
displacements (from 8.45 to $8.58 \mathrm{ppm}$ ) also attributed to hydrogen bonding interactions with the $\mathbf{d A Z O}_{\mathbf{i}}$ carboxylic acid. Such small shift is explained by the low complexation degree of these supramolecular BCs, see Table 1. The acidic proton signal $\left(H_{C}\right)$ was very broad and was not visible in the ${ }^{1} \mathrm{H}$ NMR spectrum. It is particularly noteworthy that in both systems the protons close to the hydrogen bonds experienced slight displacements. For example, protons of the pyridine ring of the 2,6-diacylaminopyridine units $\left(H_{P Y}\right)$ are shifted by around $+0.05 \mathrm{ppm}$. NOESY was also applied to further evaluate hydrogen bonding in these materials. The ${ }^{1} \mathrm{H}-{ }^{1} \mathrm{H}$ NOESY spectrum of $\left\{\mathbf{P E G}_{\mathbf{2}}-\boldsymbol{b}\right.$-PDAP॰tAZO $\left.\mathbf{O}_{\mathrm{i}}\right\}$ is shown in Figure S6, and depicts significant cross-peaks between $H_{A}$ and $H_{B}$, thus indicating that these groups are close in space because of H-bonding interactions. However, NOESY experiments of BCs with $\mathbf{d A Z O}$ id not show any additional information.

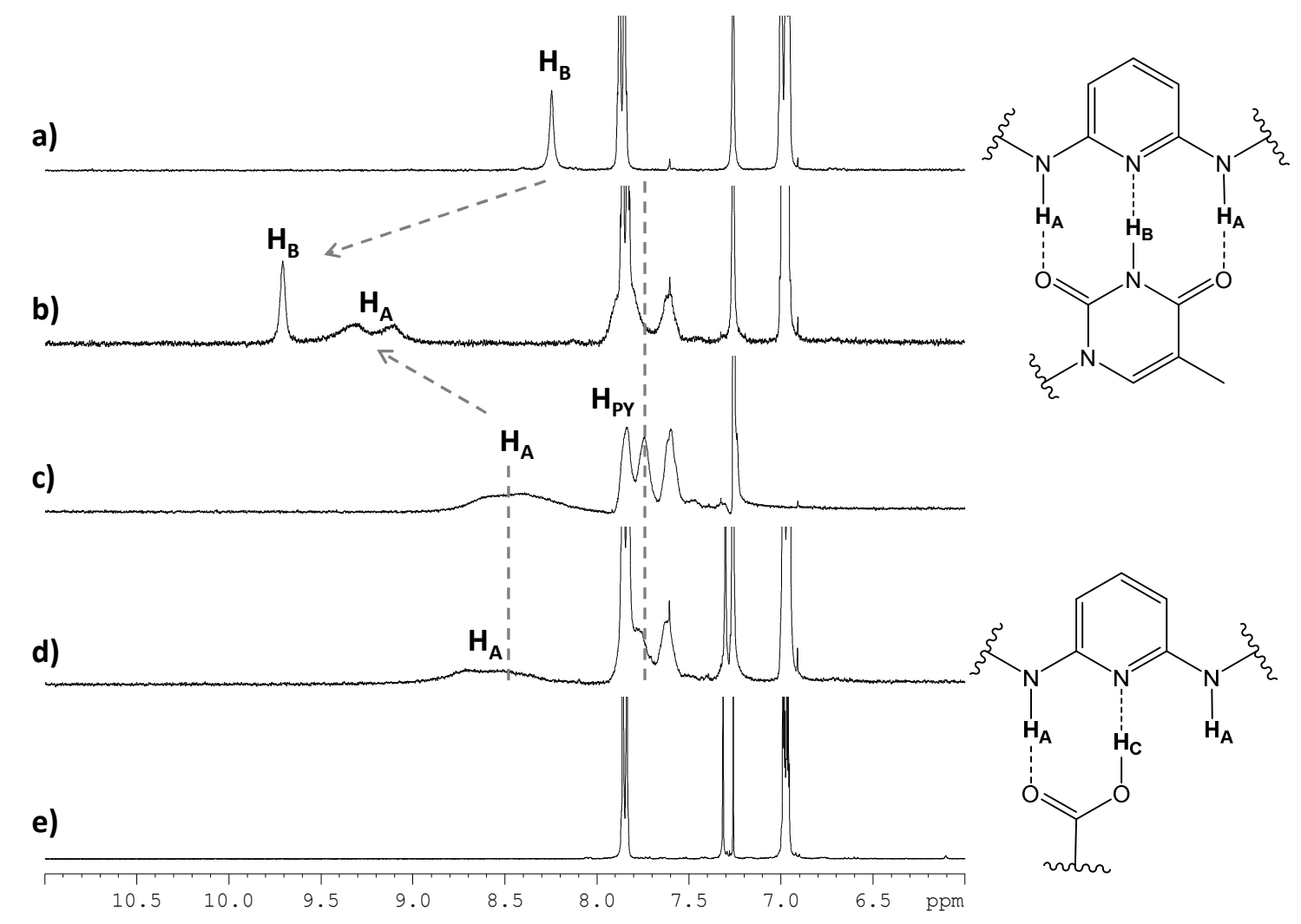




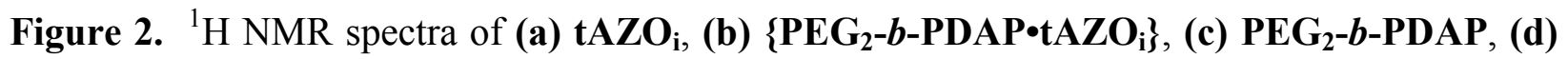
$\left\{\mathbf{P E G}_{\mathbf{2}}-\boldsymbol{b}\right.$-PDAP•dAZO $\left.\mathbf{i}\right\}$, and (e) dAZO

Temperature dependent NMR experiments can also provide with valuable information about the strength of hydrogen bonding, and therefore the ${ }^{1} \mathrm{H}$ NMR spectra of the supramolecular BCs were also recorded in solution in the 25 to $55^{\circ} \mathrm{C}$ range (Figure 3). On heating the $\mathbf{t A Z \mathbf { O } _ { \mathbf { i } }}$ complexes, the $H_{A}$ and $H_{B}$ signals moved steadily from 9.23 and 9.71 to 8.95 and $9.01 \mathrm{ppm}$, respectively, while for the $\mathbf{d A Z O}_{\mathbf{i}}$ complexes, the $H_{A}$ signal shifted from 8.61 to $8.36 \mathrm{ppm}$. When the solutions were cooled from 55 to $25^{\circ} \mathrm{C}$, all displaced signals went back to their original chemical shifts. These gradual displacements are attributed to dissociation and recovery of the hydrogen bonds between complementary units on heating and cooling, respectively, and highlight their thermoreversible character. ${ }^{42}$

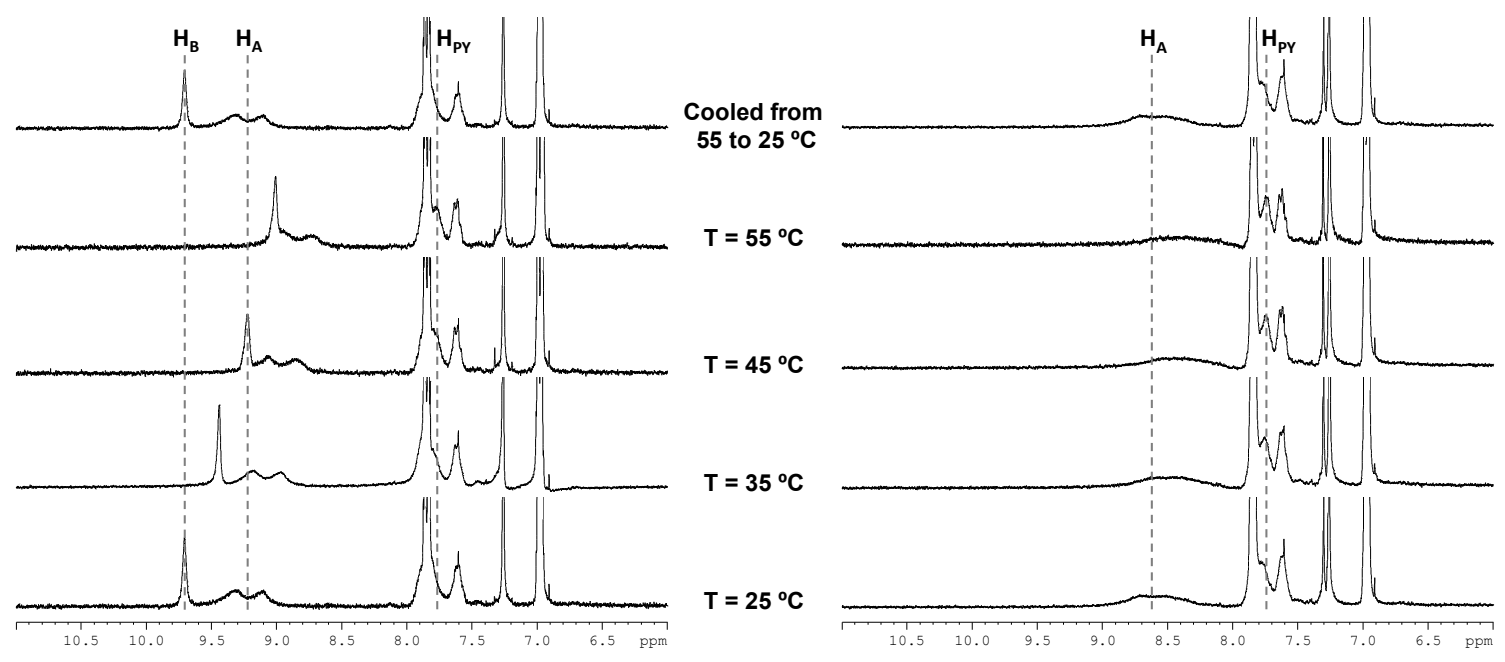

Figure 3. ${ }^{1} \mathrm{H}$ NMR spectra in $\mathrm{CDCl}_{3}$ of $\left\{\mathbf{P E G}_{\mathbf{2}}-\boldsymbol{b}\right.$-PDAP॰tAZO $\left.\mathbf{i}\right\}$ (left) and $\left\{\mathbf{P E G}_{\mathbf{2}}-\boldsymbol{b}\right.$ PDAP•dAZO $\left.{ }_{i}\right\}$ (right) taken at different temperatures (bottom to top: spectra registered on heating and after cooling down again to room temperature). 
An overview of the IR response of $\left\{\right.$ PDAP•tAZO $\left._{\mathbf{i}}\right\}$ and $\left\{\right.$ PDAP•dAZO $\left._{\mathbf{i}}\right\}$, in the complete frequency range, is shown in Figure S7 (Supporting Information). The FTIR spectra of the complexes display several changes respect to the azocompounds and polymer precursors due to the formation of specific interactions between the PDAP units and the azocompounds. In the case of supramolecular polymers containing $\mathbf{t A Z O}$ (Figure S8a), the significant modifications of the stretching vibration modes of the carbonyl and amide groups, $\mathrm{C}=\mathrm{O}$ st and $\mathrm{N}-\mathrm{H} s t$, as well as of the bending bands associated to the amide groups, $\mathrm{N}-\mathrm{H} \delta$, are additional signatures of hydrogen bonding between the 2,6-diacylaminopyridine cores and the thymine units. The IR profiles do not vary to a great extent with temperature, as a consequence of the stability of these interactions in the bulk, and only slight variations are observed in the $\mathrm{C}=\mathrm{O}$ st and $\mathrm{N}-\mathrm{H} \delta$ regions, (see Figure S9a). The IR C=Ost region of the $\mathbf{d A Z O} \mathbf{Z}_{\mathbf{i}}$ complexes (Figure S8b), is dominated by two main bands at around $1690 \mathrm{~cm}^{-1}$ (attributed to hydrogen bonded acid groups of $\mathbf{d A Z O} \mathbf{O}_{\mathbf{i}}$ and to amide groups of 2,6-diacylaminopyridine) and $1730 \mathrm{~cm}^{-1}$ (assigned to ester and free $\mathbf{d A Z O} \mathbf{O}_{\mathbf{i}}$ acid groups). On heating above the melting temperature (Figure S9b), the $1690 \mathrm{~cm}^{-1}$ region undergoes a relative decrease while the $1730 \mathrm{~cm}^{-1}$ band broadens, and this is accompanied with a noticeable decrease of the $\mathrm{N}-\mathrm{H} s t$ signals (below $3400 \mathrm{~cm}^{-1}$ ). These simultaneous variations indicate partial breakage of hydrogen bonds between the acid groups of $\mathbf{d A Z O} \mathbf{O}_{\mathbf{i}}$ and the amide groups of the 2,6-diacylaminopyridine cores. The previous changes are reversed on cooling, and the behavior is reproducible on further heating and cooling cycles, in consistency with the NMR results shown above.

Thermal Characterization of Precursors and Supramolecular BCs. The azocompound precursors and derived supramolecular polymers showed good thermal stability, as determined by TGA, with onset temperatures ( $T_{\text {onset }}$ ) associated to mass loss above $200^{\circ} \mathrm{C}$ (Table 1). 
Evolution of volatiles due to the presence of residual solvents or water was not observed. The phase behavior of the building components and supramolecular polymers was evaluated by DSC (Table 1). Properties of the PDAP homopolymer, the PEG macro-CTAs, PEG $\mathbf{X}-\mathbf{C T A}$, and the PEG $_{\mathbf{X}}$ - $\boldsymbol{b}$-PDAP BCs were previously reported ${ }^{39}$ and relevant data are included in Table $\mathbf{1}$ as reference. The $\mathbf{P E G}_{\mathbf{X}} \mathbf{b}$-PDAP BCs are amorphous and only exhibit a single glass transition (no melting transitions were observed) indicating compatibility between blocks. The low molar mass azocompound $\mathbf{A} \mathbf{A Z O} \mathbf{O}_{\mathbf{i}}$ is a crystalline material that melts to give an isotropic liquid phase at $166^{\circ} \mathrm{C}$, while $\mathbf{d A Z O} \mathbf{O}_{\mathbf{i}}$ exhibits semicrystalline behavior, showing a glass transition at $T_{\mathrm{g}}=68^{\circ} \mathrm{C}$ and a melting point at $T_{\mathrm{m}}=141^{\circ} \mathrm{C}$ (see Figure $\mathbf{S 1 0}$ in Supporting Information).

All the supramolecular polymers appear homogeneous under POM, with no signs of segregation between the individual components upon subsequent heating and cooling cycles, corroborating the formation of single-like materials.

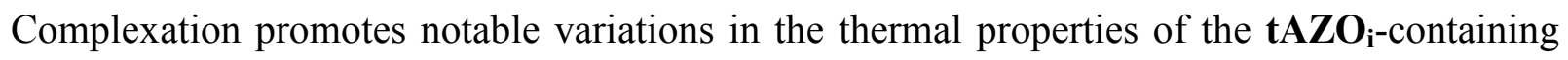
supramolecular polymers compared to their precursors (Figure 4). The heating curve of \{PDAP•tAZO $\mathbf{i}_{\mathrm{i}}$ is shown as a reference in Figure 4(a), and displays a $T_{g}$ at around $35^{\circ} \mathrm{C}$

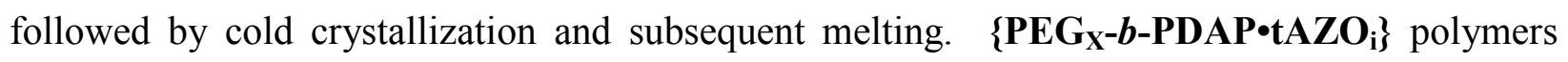
also depict the previous transitions related to the crystalline complexed PDAP block, accompanied by melting of the PEG block at $40-48{ }^{\circ} \mathrm{C}$, see Figure 4(b) and 4(c). The appearance of several thermal events ascribable to the different blocks suggests that complexation induces microphase separation by decreasing the miscibility between blocks.

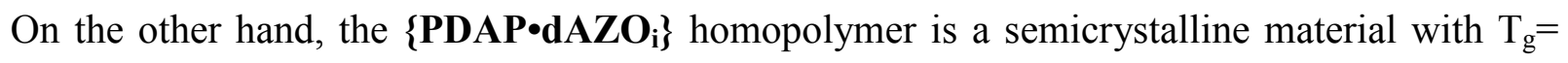
$77^{\circ} \mathrm{C}$ and $\mathrm{T}_{\mathrm{m}}=136^{\circ} \mathrm{C}$, (Figure 5, trace a). The corresponding supramolecular BCs, $\left\{\mathbf{P E} \mathbf{G}_{\mathbf{X}} \boldsymbol{- b}\right.$ - 
PDAP•dAZO ${ }_{i}$, show an additional glass transition at lower temperatures in the $4-15^{\circ} \mathrm{C}$ range, together with a weak thermal event related to melting of the PEG blocks at $40-52^{\circ} \mathrm{C}$ (see inset in Figure 5). These results seem to confirm that complexation promotes microphase separation

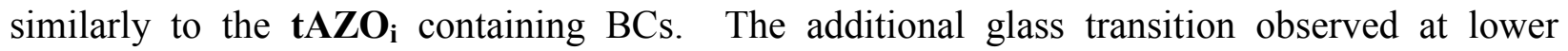
temperatures $\left(T_{g} \sim 4-15^{\circ} \mathrm{C}\right)$ can be attributed to the presence of uncomplexed sample, $\left\{\mathbf{P E} \mathbf{G}_{\mathbf{X}}-\boldsymbol{b}\right.$ PDAP $\}$, caused by the low complexation degree yielded in these $\mathbf{d A Z O} \mathbf{O}_{\mathbf{i}}$-based materials (0.30).

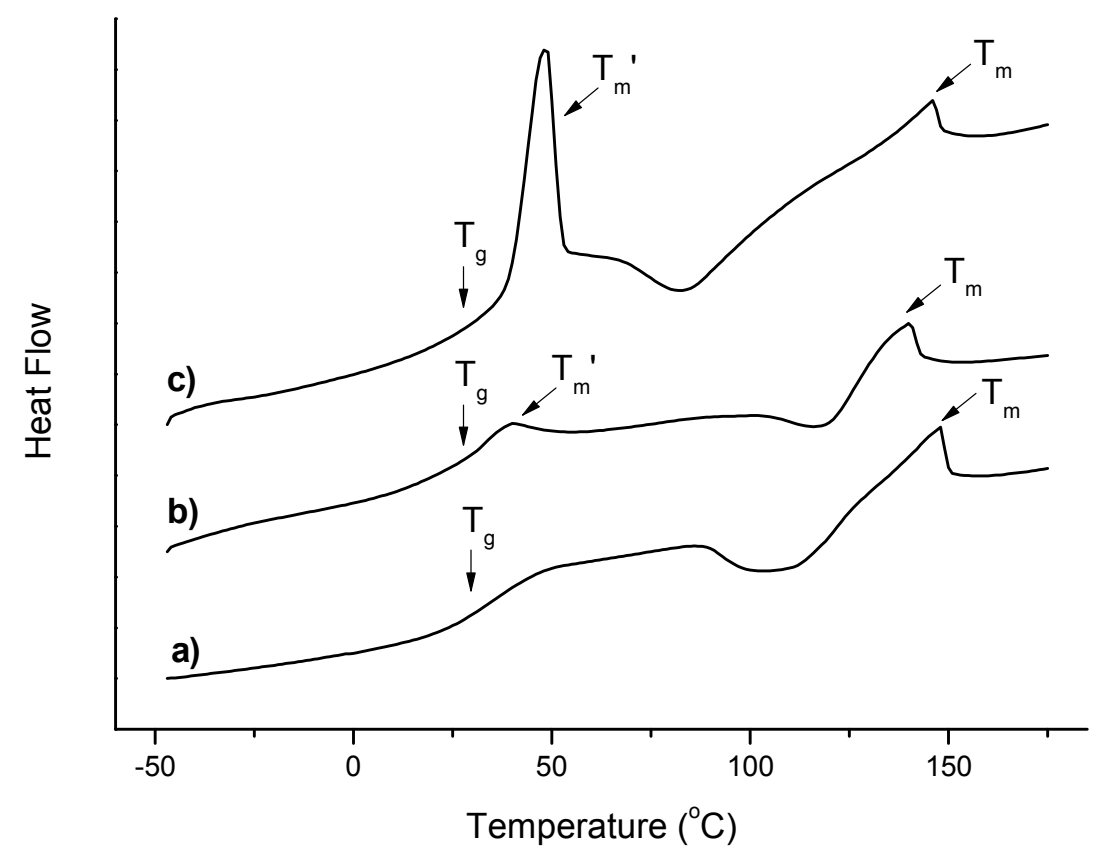

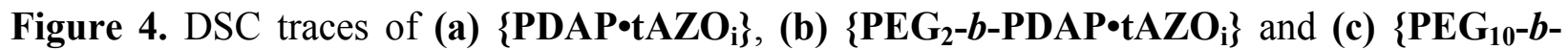
PDAP•tAZO ${ }_{i}$ \} corresponding to the second heating scans $\left(10^{\circ} \mathrm{C} \mathrm{min}^{-1}\right.$, Exo down $)$ 


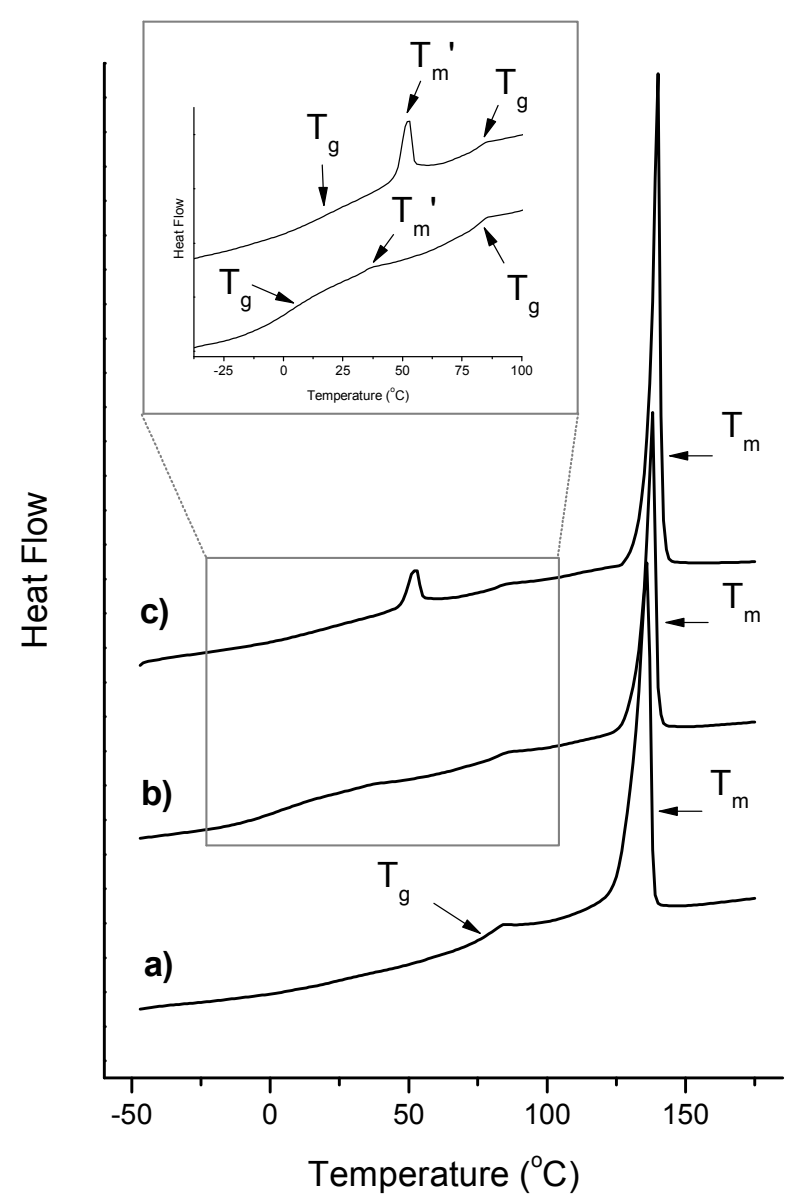

Figure 5. DSC traces of (a) $\{$ PDAP•dAZO $\}$, (b) $\left\{\mathbf{P E G}_{\mathbf{2}}-\boldsymbol{b}-\mathbf{P D A P} \bullet d A Z O_{i}\right\}$ and (c) $\left\{\mathbf{P E G}_{\mathbf{1 0}}-\boldsymbol{b}\right.$ PDAP•dAZO $\left.\mathbf{i}_{\mathrm{i}}\right\}$ corresponding to the second heating scans $\left(10^{\circ} \mathrm{C} \mathrm{min}^{-1}\right.$, Exo down $)$

Self-Assembly of the supramolecular BCs in water. We have recently reported that the uncomplexed copolymers under study form spherical micellar self-assemblies with a diameter of approx. $21 \mathrm{~nm}$, for $\mathbf{P E G}$ - $\boldsymbol{b}$-PDAP, and $32 \mathrm{~nm}$, for $\mathbf{P E G}_{\mathbf{1 0}} \mathbf{- b}$-PDAP, as determined by DLS (18 and $25 \mathrm{~nm}$ as determined by TEM). ${ }^{39}$ We now investigate the self-assembled structures of the supramolecular BCs, which were prepared by the co-solvent method using THF/water, and whose formation was monitored by turbidity (see Figure S11 in Supporting Information). 
While $\mathbf{d A Z O} \mathbf{O}_{\mathrm{i}}$-containing supramolecular BCs precipitated during dialysis, indicating the collapse of the assemblies in water, we obtained stable dispersions of $\left\{\mathbf{P E G}_{\mathbf{2}}-\boldsymbol{b}-\mathbf{P D A P} \mathbf{A} \mathbf{A Z O} \mathbf{O}_{\mathbf{i}}\right\}$ and $\left\{\right.$ PEG $\left._{10}-b-P D A P \bullet t A Z O_{i}\right\}$

Rotello and co-workers showed that the efficiency of H-bonding post-functionalization on polymers containing pendant nucleobase analogues rely on the balance between intramolecular polymer-polymer binding and intermolecular polymer-guest binding. ${ }^{43,44}$ Therefore, in solution recognition will depend on the tendency of the pendant diacylaminopyridines to selfdimerization compared to the binding affinity of the complementary pair diacylaminopyridinecarboxylic acid or diacylaminopyridine-thymine. However, in DAP polymers, the DAP-DAP association is low and hardly competitive for instance in the DAP-thymine recognition process. $^{44,45}$

Carboxylic acid-diacylaminopyridine recognition was used by Kato to prepare side chain liquid crystalline polymers demonstrating the feasibility of the functionalization. ${ }^{46}$ However, even if it is stabilized by the liquid crystal state, this interaction is probably not strong enough in aqueous solution (water is a competitive solvent) to form stable self-assemblies. Among other factors, the strength of the association increases with the number of hydrogen bonds ${ }^{23}$ so the use of thymine instead of the carboxylic acid renders stable polymeric nanoparticles. To confirm this point and discard a steric effect on the dendron complexation, a new acarboxylic acid analogue of tAZO, i.e. with one azobenzene $\left(\mathbf{a c A Z O}_{\mathbf{i}}\right.$ ), was synthesized (see Supporting Information). Two new supramolecular complexes with $\mathbf{P E G}_{\mathbf{1 0}} \mathbf{- b}$-PDAP with degrees of complexation of 0.30 and 1 were prepared but with none of them stable self-assemblies were obtained. This finding stresses our hypothesis that the stability of self-assemblies is influence by the H-bond strength more than by the steric hindrance imposed by the dendron. 
Thus, all further studies were perfomed for $\left\{\mathbf{P E G}_{\mathbf{2}}-\boldsymbol{b}-\mathbf{P D A P} \mathbf{P} \mathbf{A Z O}_{\mathbf{i}}\right\}$ and $\left\{\mathbf{P E G}_{\mathbf{1 0}} \mathbf{- b}\right.$ PDAP•tAZO $\mathrm{i}_{\mathrm{i}}$. The CAC of these supramolecular BCs in water was determined by fluorescence, using Nile Red (Figure S12 in Supporting Information). Values of 28 and 42 $\mu \mathrm{g} / \mathrm{mL}$ were obtained for $\left\{\mathbf{P E G}_{\mathbf{2}}-\boldsymbol{b}-\mathbf{P D A P} \bullet \mathbf{t A Z O} \mathbf{O}_{\mathbf{i}}\right\}$ and $\left\{\mathbf{P E G}_{\mathbf{1 0}}-\boldsymbol{b}-\mathbf{P D A P} \bullet \mathbf{t A Z O} \mathbf{O}_{\mathbf{i}}\right\}$, respectively, as the threshold concentration of the amphiphilic polymer above which the polymer chains start to associate. These values correlate with their thermodynamic stability and are typical for amphiphilic BCs. $^{47}$

The stability of the self-assemblies suspensions was followed by temperature dependent DLS experiments. The resulting self-assemblies were stable over 8 days at $25^{\circ} \mathrm{C}$, after 30 days not precipitation was observed but polydispersity was high to obtain a stable measurement (see Figure S13 in Supporting Information). DLS experiments were also recorded at 25, 35, 45, and $55^{\circ} \mathrm{C}$, which were the temperatures selected for NMR experiments, and self aseemblies were stable at 25 and $35^{\circ} \mathrm{C}$ but not at 45 and $55^{\circ} \mathrm{C}$. Reformation of the self assemblies was not observed upon cooling.

The morphology of the self-assemblies was firstly investigated by TEM. It was found that

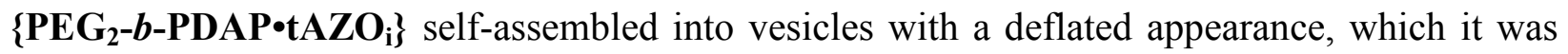
attributed to water removal during preparation for sample inspection (Figure 6a). The aqueous suspension of the vesicles was then inspected by cryo-TEM, by quenching the sample into liquid ethane at $-170{ }^{\circ} \mathrm{C}$, showing spherical vesicles having a membrane thickness around $10 \mathrm{~nm}$ (Figure 6b). The mean average hydrodynamic diameter $\left(D_{\mathrm{h}}\right)$ of these vesicles evaluated by DLS was $345 \mathrm{~nm}$ (Figure 7), which is in good agreement with cryo-TEM observations. It is worth emphasizing that the parent $\mathbf{P E G}_{\mathbf{2}}-\boldsymbol{b}$-PDAP BC formed spherical micelles and upon functionalization via $\mathrm{H}$-bonding with $\mathbf{t A Z O}$, vesicles are formed. 
a)

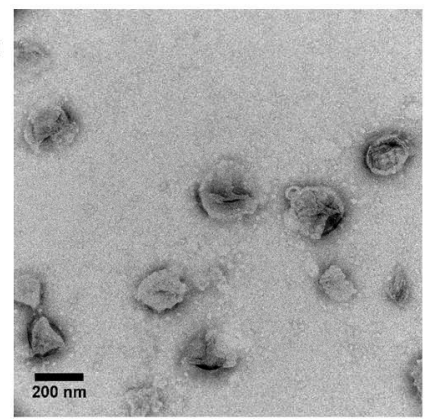

d)

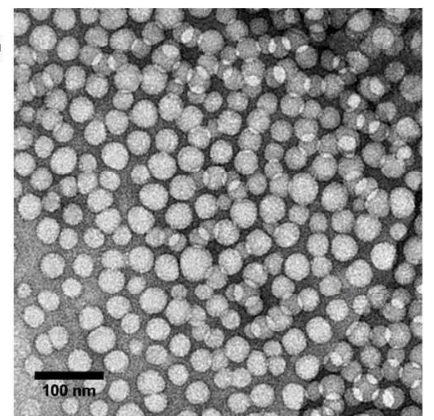

b)

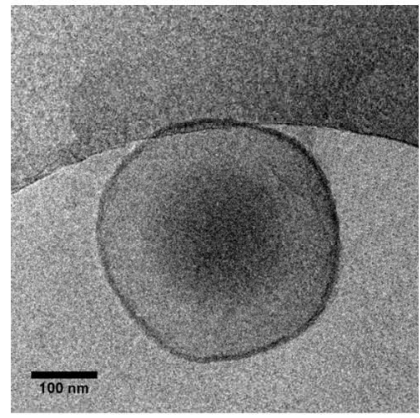

e)

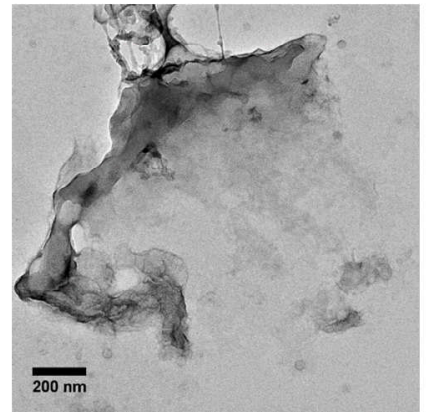

c)

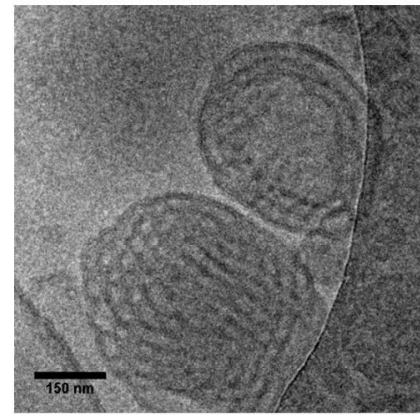

f)

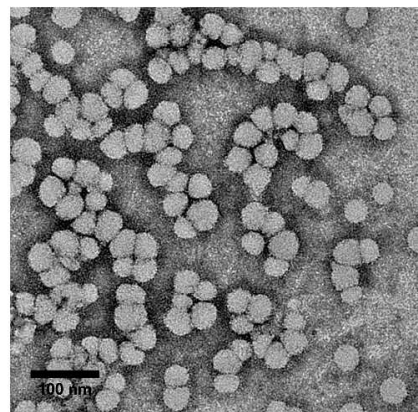

Figure 6. (a) TEM image of $\left\{\mathbf{P E G}_{\mathbf{2}}-\boldsymbol{b}\right.$-PDAP•tAZO $\left.{ }_{\mathrm{i}}\right\}$ non-irradiated vesicles. Cryo-TEM images of $\left\{\mathbf{P E G}_{\mathbf{2}}-\boldsymbol{b}\right.$-PDAP•tAZO $\left.\mathbf{i}\right\}$ vesicles (b) before and (c) after UV irradiation. TEM images of $\left\{\mathbf{P E G}_{\mathbf{1 0}} \mathbf{b} \boldsymbol{b}\right.$-PDAP•tAZO $\left.\mathbf{i}\right\}$ micelles (d) before, (e) after irradiation and (f) $24 \mathrm{~h}$ after irradiation. 
a)

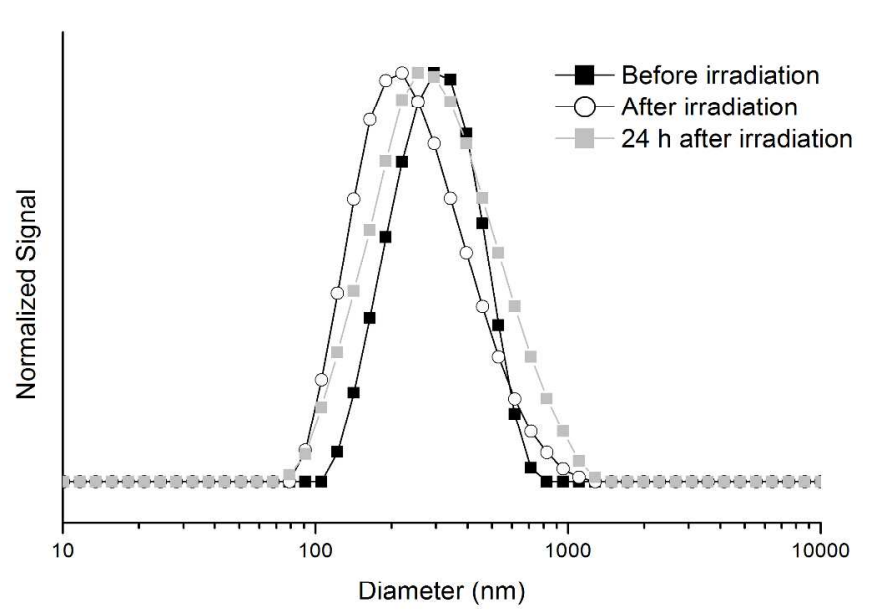

b)

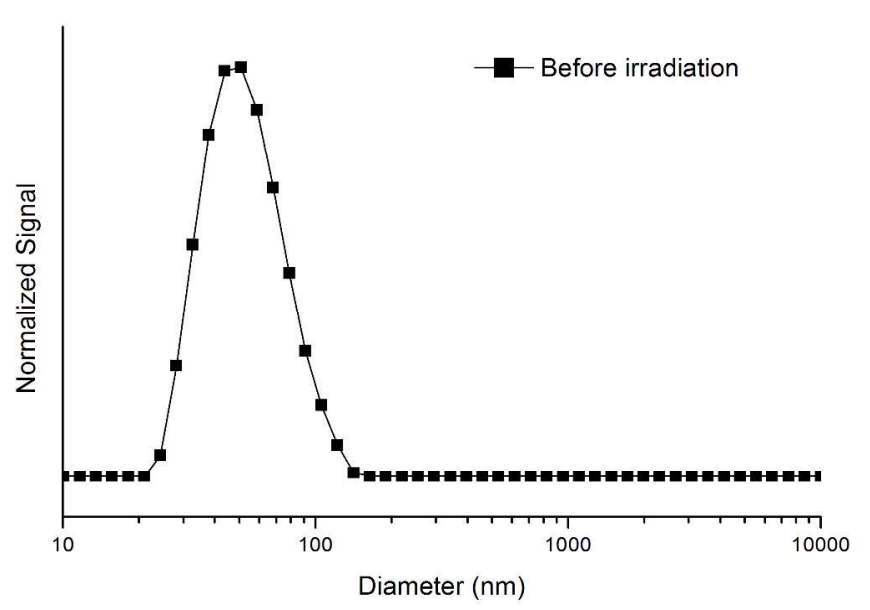

Figure 7. DLS measurements of a water suspension of (a) $\left\{\mathbf{P E G}_{\mathbf{2}}-\boldsymbol{b}-\mathbf{P D A P} \bullet \mathbf{t A Z O} \mathbf{O}_{\mathbf{i}}\right\}$ vesicles before and after irradiation for $10 \mathrm{~min}$ and (b) $\left\{\mathbf{P E G}_{\mathbf{1 0}} \mathbf{b}\right.$-PDAP•tAZO $\left.\mathbf{P}\right\}$ non-irradiated micelles (after irradiation, accurate DLS measurements were not possible due to a very high polydispersity).

TEM images of $\left\{\mathbf{P E G}_{\mathbf{1 0}}-\boldsymbol{b}\right.$-PDAP•tAZO $\left.\mathbf{P}\right\}$ show the formation of spherical micelles with a diameter of approx. $40 \mathrm{~nm}$ (Figure 6d). The average $D_{\mathrm{h}}$ determined by DLS was $51 \mathrm{~nm}$ (Figure 7). Therefore, and unlike its analogue with the shorter PEG block, complexation of $\mathbf{P E G}_{\mathbf{1 0}} \mathbf{- b}$ - 
PDAP with $\mathbf{t A Z O}$ i does not promote a change of the self-assembled structures from spherical micelles to vesicles, albeit larger micelles (20 $\mathrm{nm}$ increase on diameter) are observed respect to the parent $\mathrm{BC}$. The previous results can be rationalized in terms of the macromolecular structure

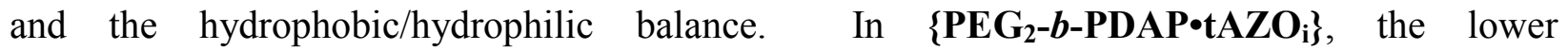
hydrophilic/hydrophobic weight balance, which change from approx. 35/65 to 18/82 upon complexation, seems to stabilize the vesicular morphology, while the higher molecular weight of the hydrophilic blocks in $\left\{\mathbf{P E G}_{\mathbf{1 0}}-\boldsymbol{b}\right.$-PDAP•tAZO $\left.\mathbf{i}\right\}$ allows to retain the spherical micellar morphology under the present experimental conditions.

Light-responsive behavior of the supramolecular BCs. The photoresponse of $\left\{\mathbf{P E G}_{2}-\boldsymbol{b}\right.$ -

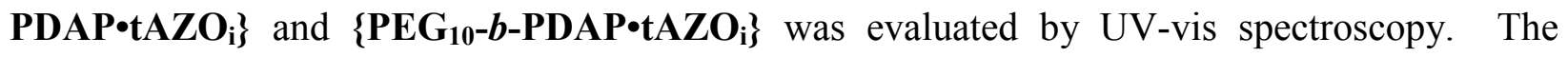
spectra of the amphiphilic BCs in THF solution showed the characteristic profile of the $E$-isomer of the azobenzene chromophore. This includes an intense band at $362 \mathrm{~nm}$, related to the $\pi-\pi^{*}$ transition, together with a weak absorption band at about $450 \mathrm{~nm}$, corresponding to the symmetry forbidden $\mathrm{n}-\pi^{*}$ transition of the $E$-azobenzene. The spectra of micelles and vesicles in water evidenced broadening and hypsochromic shifting of the $\pi-\pi^{*}$ band (Figure 8) compared to the results of the supramolecular BCs in THF. The absorption band shifted down to $348 \mathrm{~nm}$, which indicates the predominant formation of azobenzene H-aggregates. Furthermore, two additional contributions at higher wavelengths were observed: one at $362 \mathrm{~nm}$, corresponding to the value determined for the non-aggregated $E$-azobenzene detected in solution, and other at $378 \mathrm{~nm}$, characteristic of J-aggregates.

The sensitivity of the self-assemblies to UV-light was assessed by UV illuminating the respective suspensions and simultaneously recording changes in their UV-vis spectra (Figure 8). A remarkable decrease in $\pi-\pi^{*}$ absorbance was observed accompanied by a notable increase of 
the absorbance at $450 \mathrm{~nm}$ due to the photoinduced $E$-to- $Z$-azobenzene isomerization. After 10 min of light exposure, only slight changes were observed in the UV-vis spectrum indicating that a photostationary state was reached. After $24 \mathrm{~h}$ in the dark, UV-vis spectra started to recover the initial shape due to thermal $Z$-to- $E$ back isomerization.

a)

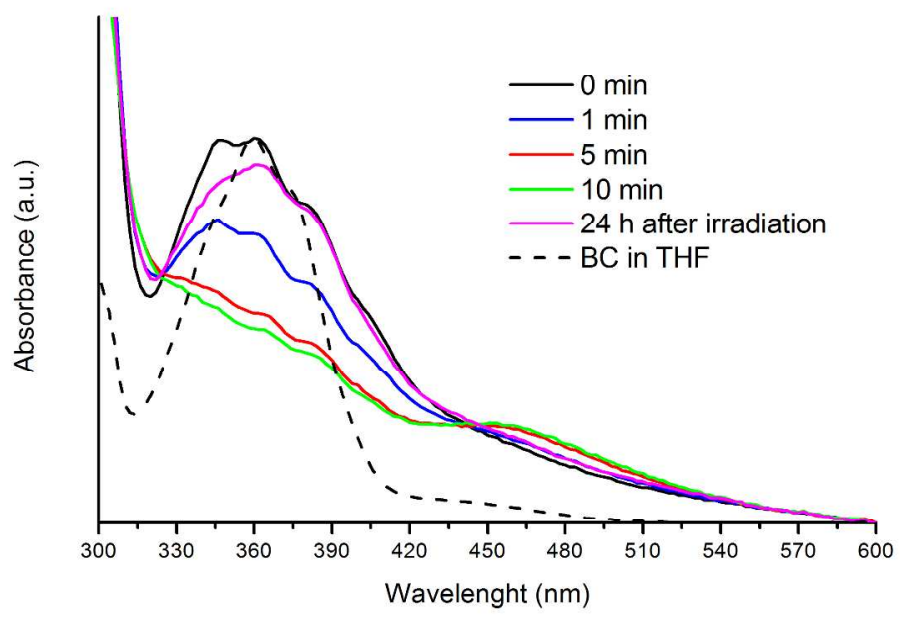

b)

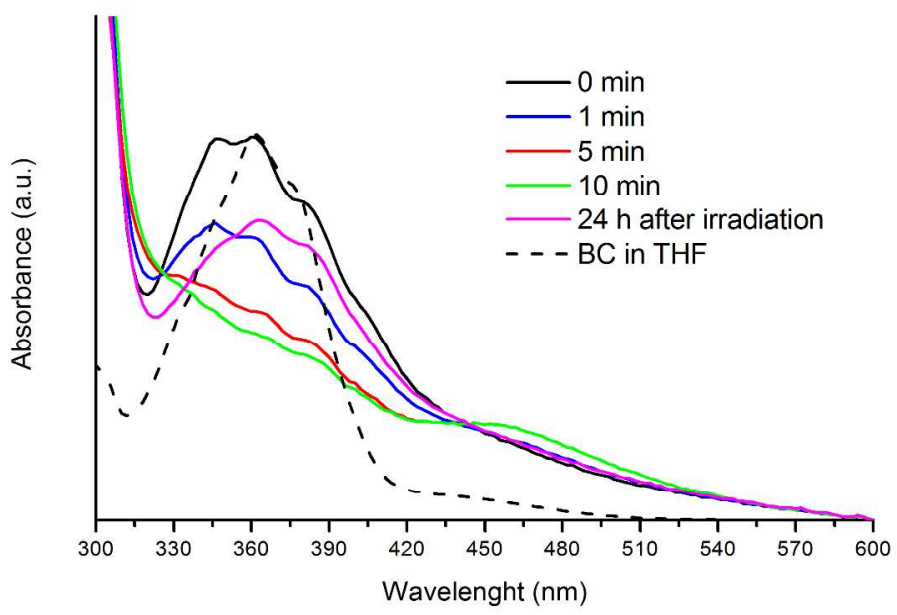

Figure 8. UV-Vis spectra of (a) $\left\{\mathbf{P E G}_{\mathbf{2}}-\boldsymbol{b}-\mathbf{P D A P} \bullet \mathbf{A Z O} \mathbf{O}_{\mathbf{i}}\right\}$ and (b) $\left\{\mathbf{P E G}_{\mathbf{1 0}}-\boldsymbol{b}-\mathbf{P D A P} \bullet \mathbf{A Z O} \mathbf{O}_{\mathbf{i}}\right\}$ in a $5 \times 10^{-6} \mathrm{M}$ THF solution and UV irradiated self-assemblies $\left(1 \mathrm{mg} \mathrm{mL}^{-1}\right.$ suspensions $)$ for different times. 
Potential morphological changes upon 10 min UV irradiation were further studied by TEM, Cryo-TEM and DLS. For $\left\{\mathbf{P E G}_{\mathbf{2}}-\boldsymbol{b}\right.$-PDAP॰tAZO $\left.\mathbf{i}\right\}$, cryo-TEM images show the presence of wrinkled vesicles (Figure 6c) of smaller average $D_{\mathrm{h}}$ respect to the sample prior to exposure, around $225 \mathrm{~nm}$, as calculated by DLS (Figure 7). TEM images of irradiated \{PEG $_{\mathbf{1 0}} \mathbf{- b}$ PDAP•tAZO $\mathbf{O}_{\text {i }}$ micelles taken immediately after UV illumination show disruption of the assemblies and regions of material without clear morphology (Figure 6e). Accordingly, accurate measurements by DLS were not possible due to a very high increase of polydispersity of the selfassemblies size in solution. TEM images of irradiated suspensions taken after maintaining the sample $24 \mathrm{~h}$ in the dark at room temperature were additionally registered. Under these conditions, thermal $Z$-to- $E$ back isomerization of the azobenzene takes place and images show that micelles are at least partially recovered (Figure 6f). To gain additional information about the process, ${ }^{1} \mathrm{H}$ NMR of a solution of $\left\{\mathbf{P E G}_{\mathbf{1 0}} \boldsymbol{- b}\right.$-PDAP•tAZO $\left.\mathbf{P}\right\}$ in $\mathrm{CDCl}_{3}$ was registered after 15 min irradiation (Figure S14 in supporting information). The only observed differences were the presence of new peaks at around 6.88 and $6.75 \mathrm{ppm}$ corresponding to aromatic protons of the $Z$ azobenzene. However, peaks corresponding to the protons involved in the H-bonding were not shifted. This seems to probe that isomerization only influences the azobenzene packing and/or hydrophobic/hydrophilic balance and not H-bonding association.

Self-assemblies of the parent $\mathbf{P E G} \mathbf{X}-\boldsymbol{b}$-PDAP copolymers and the supramolecular BCs $\left\{\mathbf{P E G}_{\mathbf{X}}-\boldsymbol{b}\right.$-PDAP•tAZO $\left.\mathbf{i}\right\}$, as well as their light responses, were investigated with detail by SAXS. Figure 9a shows the SAXS profile as a function of the module of the scattering vector $q$, for different aggregates in water $(q=4 \pi / \lambda \sin (\theta)$, being $2 \theta$ the scattering angle). In the case of the PEG $_{\mathbf{X}} \boldsymbol{b}$-PDAP BCs, the SAXS curves can be described by the scattering of a distribution of 
spheres with different diameters. ${ }^{48,49}$ The scattering form factor for a sphere of radius $\mathrm{R}$ is given by $\mathbf{E q} 1$,

$F_{S}(q, R)=\left[\frac{3[\sin (q R)]-q R \cos (q R)}{(q R)^{3}}\right]^{2}$

For $\mathbf{P E G}_{2}$ - $\boldsymbol{b}$-PDAP the distribution was centered around diameters $(2 R)$ of approx. $18 \mathrm{~nm}$ and for $\mathbf{P E G}_{\mathbf{1 0}}$-b-PDAP around $25 \mathrm{~nm}$ (Figure 9b), which is consistent with DLS analysis and TEM observations. $^{39}$

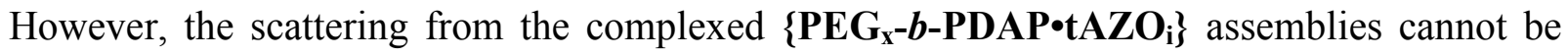
fitted with a simple sphere distribution model. In the case of $\left\{\mathbf{P E G}_{\mathbf{2}}-\boldsymbol{b}\right.$-PDAP•tAZO $\left.\mathbf{P}\right\}$ cryoTEM images (Figure 6b) showed that the assemblies are vesicles with a diameter larger than $300 \mathrm{~nm}$ and a wall thickness of just a few nanometers. Therefore, due to the vesicles dimensions, SAXS profiles only give information about the their walls. Taking this under consideration and using the Guinier approximation for planar objects, it is possible to obtain the radius of gyration (Eq 2) from the scattering curve of the supramolecular assembly $\left\{\mathbf{P E G}_{\mathbf{2}}-\boldsymbol{b}\right.$ PDAP•tAZO $\}_{i} \cdot{ }^{50}$ The radius of gyration for a planar object with large lateral dimensions is related to its thickness (Eq 3),

$I(q) \sim q^{-2} \exp \left(-q^{2} R_{g}^{2}\right)$

$d_{t}^{2}=12 R_{g}^{2}$

Figure 9c shows the Guinier plot for $\left\{\mathbf{P E G}_{\mathbf{2}}-\boldsymbol{b}\right.$-PDAP•tAZO $\left.\mathbf{i}\right\}$ in the dark. Fitting the scattering to the Guinier approximation, provides with a vesicle wall thickness of around $10 \mathrm{~nm}$, which is consistent with our cryo-TEM observations (Figure 6b). 
With the aim to monitor the modifications induced on the morphology of the supramolecular assemblies by UV light exposure, real time SAXS experiments were also performed on the tAZO $_{\mathbf{i}}$ containing supramolecular assemblies. Figure 10a shows the scattering curves corresponding to $\left\{\mathbf{P E G}_{\mathbf{2}}-\boldsymbol{b}-\mathbf{P D A P} \bullet \mathbf{A Z Z O} \mathbf{O}_{\mathbf{i}}\right\}$ vesicles for selected UV illumination times. The UV light induced subtle changes in the scattering curves, especially at large values of $q$, although these could not be quantified due to excessive noise in the measurements. Nevertheless, Guinier analysis of the curves allowed to estimate the thickness of the vesicle wall as a function of the UV exposure time, and the results are presented in the inset of Figure 10a. UV illumination induced thining of the vesicles wall, and at long exposure times, the slope at low $q$ increases probably as consequence of their further disruption.

On the other hand, we have seen earlier by TEM than $\left\{\mathbf{P E G}_{\mathbf{1 0}}-\boldsymbol{b}-\mathbf{P D A P} \bullet \mathbf{t A Z O} \mathbf{i}\right\}$ assembled into micelles of mean radius around $20 \mathrm{~nm}$, and thus a different scattering pattern is expected for this supramolecular BC. Although an estimation of the radius of the spherical objects can be obtained by the Guinier approximation, in this case, the whole scattering curve of these assemblies can be fitted using the form factor of a micelle model with a spherical core and Gaussian polymer chains attached to the surface $(\mathbf{E q} 4),{ }^{51,52}$

$$
\begin{gathered}
F_{\text {mic }}(q)=N_{a g g}^{2} \rho_{s}^{2} F_{s}(q, R)+N_{a g g}^{2} \rho_{c}^{2} F_{c}\left(q, R_{g a u s s}\right)+N_{a g g}\left(N_{a g g}-1\right) \rho_{c}^{2} S_{c c}(q) \\
+2 N_{a g g}^{2} \rho_{c} \rho_{s} S_{s c}(q)
\end{gathered}
$$

considering the self-correlation term $F_{S}$ of the spherical core, of radius $R$, the self-correlation of the Gaussian chains $F_{C}$, characterized by their radius of gyration $R_{\text {gauss }}$, and the crossed terms between the core and the Gaussian chains, $S_{S C}$, where the fact that the chains cannot penetrate the core is considered, and finally a crossed term between the different Gaussian chains decorating 
the core $S_{C C}{ }^{51} N_{a g g}$ is the aggregation number of the micelle, i.e. the number of molecules per micelle, $\rho_{C}$ and $\rho S$ are the total scattering length excess of the blocks in the spherical core and in the chains respectively.

Figure 10b shows the scattering of the $\left\{\mathbf{P E G}_{\mathbf{1 0}}-\boldsymbol{b}\right.$-PDAP॰tAZO $\left.\mathbf{P}\right\}$ assemblies in water, initially in the dark and after 15 min of UV illumination, and only slight changes can be observed. However, fitting their scattering to $\mathbf{E q} \mathbf{3}$ allowed to obtain the dependence of several parameters with the UV illumination time, and the results are depicted in Figure 10c. As the sample was illuminated, the number of chains per micelle decreased slightly, whereas the core radius increased slightly and the radius of gyration of the chains at the surface remained nearly constant. Since the photoresponsive groups are located within the core of the micelles, this region undergoes the strongest effects under UV exposure. Qualitatively the SAXS results are in agreement with the disruption upon UV irradiation of the micelles shown by TEM results (Figure 6e). However, it is worth to emphasize on the differences in sample environment between the two experiments. While quartz cuvettes were used for the UV irradiation of the samples subsequently investigated by TEM and DLS, glass capillaries were used for SAXS experiments, which has influence in the light absorption by the walls container being higher for glass than for quartz. This effect may provoke significant differences upon comparing quantitatively the kinetics of micelle disruption by UV illumination. 

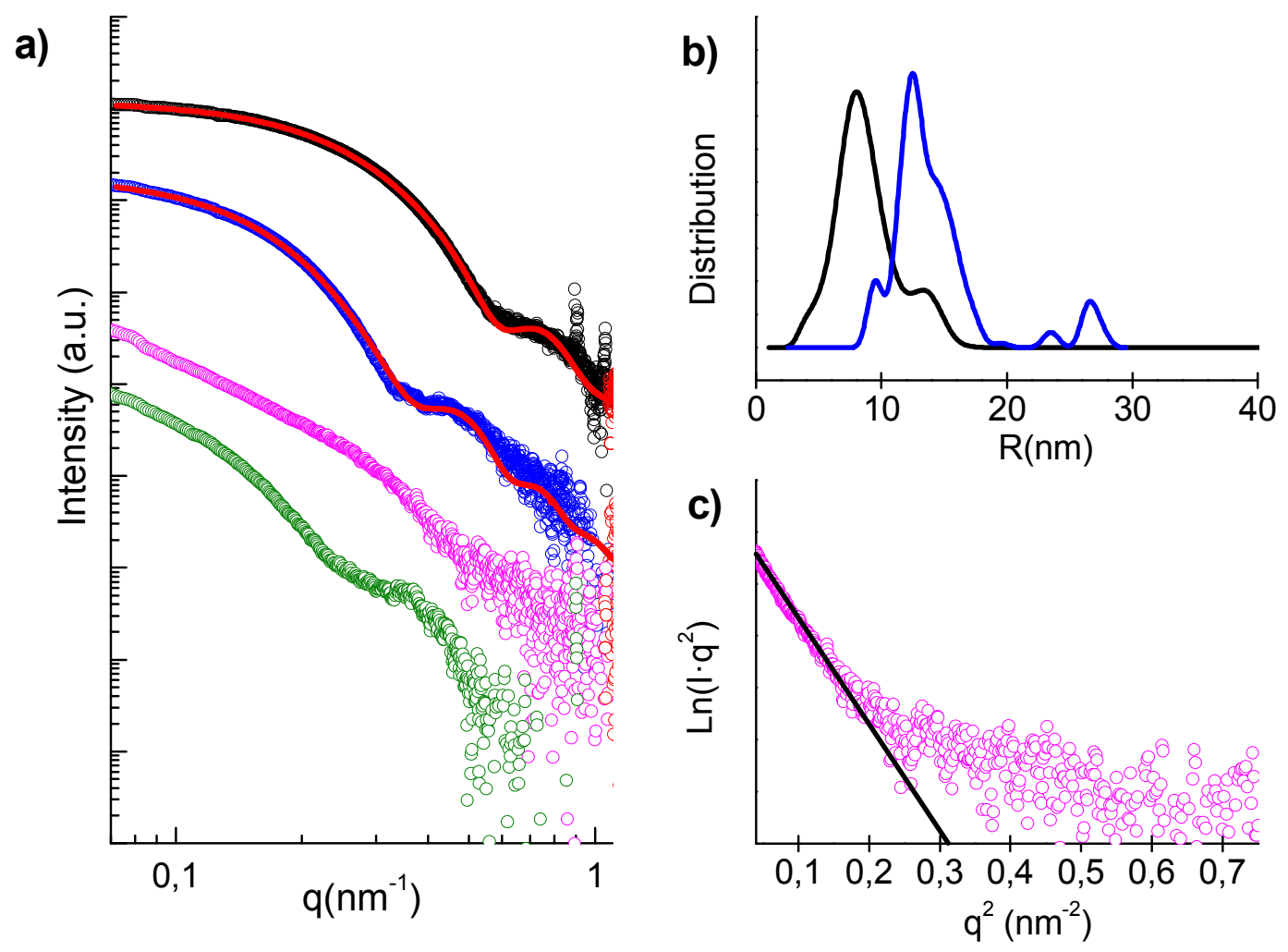

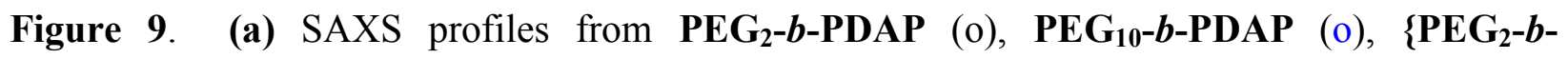

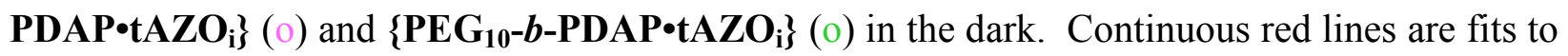
the scattering from a distribution of individual spheres. (b) Radius distribution of the spheres (according to the fit in figure a) for $\mathbf{P E G}_{\mathbf{2}}-\boldsymbol{b}$-PDAP (black) and $\mathbf{P E G} \mathbf{G}_{\mathbf{1 0}}-\boldsymbol{b}$-PDAP (blue). Guinier plot of the scattering from the supramolecular polymer $\left\{\mathbf{P E G}_{\mathbf{2}}-\boldsymbol{b}\right.$-PDAP•tAZO $\left.\mathbf{O}_{\mathbf{i}}\right\}$ in the dark. The solid line corresponds to the fit to Eq 2. 
Figure 10. (a) SAXS profiles from $\left\{\mathbf{P E G}_{\mathbf{2}}-\boldsymbol{b}\right.$-PDAP•tAZO $\left.{ }_{i}\right\}$ assemblies in dark (o), and after 5 $(\triangle), 10(\square), 15(\diamond)$ and $20(\sqrt{ })$ min of UV illumination. The inset in (a) shows the evolution of the vesicle membrane thickness as obtained by the Guinier approximation in Eq 2 and Eq 3. (b) SAXS profiles from $\left\{\mathbf{P E G}_{\mathbf{1 0}}-\boldsymbol{b}\right.$-PDAP•tAZO $\left.\mathbf{O}_{\mathbf{i}}\right\}$ assemblies in dark (o) and after $15 \mathrm{~min}$ of UV illumination $(\triangle)$. Continuous lines correspond to fit to Eq 4. (c) Variation of the relevant structural parameters included in Eq 4 related to the micelles of $\left\{\mathbf{P E G}_{\mathbf{1 0}}-\boldsymbol{b}-\mathbf{P D A P} \cdot \mathbf{t A Z O} \mathbf{O}_{\mathbf{i}}\right\}$ under UV illumination: (c1) Number of chain per micelle, (c2) Radius of the core, and (c3) Radius of gyration of the Gaussian chains forming the shell.

Light stimulated release of fluorescence probes from supramolecular BCs. The potential use of the present vesicles and micelles as stimulus responsive nanocontainers was investigated 
by encapsulation and subsequent release of fluorescent probes. $\left\{\right.$ PEG $\left._{2}-\boldsymbol{b}-\mathbf{P D A P} \mathbf{A} \mathbf{A Z O}_{\mathbf{i}}\right\}$ vesicles were tested with two fluorescent probes, since molecules with different nature can be trapped either into the hydrophilic hollow cavity or the hydrophobic membrane formed by the azobenzene moieties. Therefore, the ability to encapsulate Nile Red or Rhodamine B, which are respectively of hydrophobic and hydrophilic nature, was evaluated for these systems.

Nile Red loaded $\left\{\mathbf{P E G}_{\mathbf{2}}-\boldsymbol{b}\right.$-PDAP•tAZO $\left.\mathbf{i}_{\mathbf{i}}\right\}$ shows a strong emission from 560 to $700 \mathrm{~nm}$ while exciting at $550 \mathrm{~nm}$. Upon irradiation, an abrupt decrease on the initial fluorescence intensity at $606 \mathrm{~nm}$ was observed (Figure 11a), indicating a shift to a less hydrophobic environment. This can be due to Nile Red migrating from the membrane to the aqueous media and also to the increase in the polarity in the inner membrane caused by photoisomerization. ${ }^{17}$ When the irradiated vesicles were kept in the dark for $24 \mathrm{~h}$, the fluorescence was partially recovered, which could be attributed to partial release of the fluorescent probe.

$\left\{\right.$ PEG $_{2}-\boldsymbol{b}$-PDAP॰tAZO $\}$ vesicles loaded with Rhodamine B were also prepared by forming the assemblies in the presence of the probe, and it was estimated that 0.8 molecules of Rhodamine $\mathrm{B}$ were trapped per macromolecule of $\mathrm{BC}$ (using a feed ratio of 5:1 Rhodamine/macromolecule). Encapsulation of Rhodamine B was confirmed by observation of fluorescence dots in a dark background under confocal microscopy (Figure 12a). After $10 \mathrm{~min}$ of UV light irradiation, fluorescence dots were still visible but the fluorescence of background was more intense. These results strongly suggest that Rhodamine B is released from the interior of the vesicles to the aqueous surrounding media (Figure 12b), and evidence that the vesicle membrane became permeable to the probe after UV irradiation. 
$\left\{\right.$ PEG $_{10}-\boldsymbol{b}$-PDAP•tAZO $\left.\mathbf{i}\right\}$ micelles were only loaded with Nile Red, which should be accommodated within their hydrophobic cores. Again, an abrupt decrease of the initial fluorescence was observed after UV irradiation, indicating that the environment of the probe becomes more hydrophilic (Figure 11b). After 24h, the Nile Red fluorescence was not completely recovered, suggesting that the Nile Red was, at least partially, released into the aqueous medium.

a)

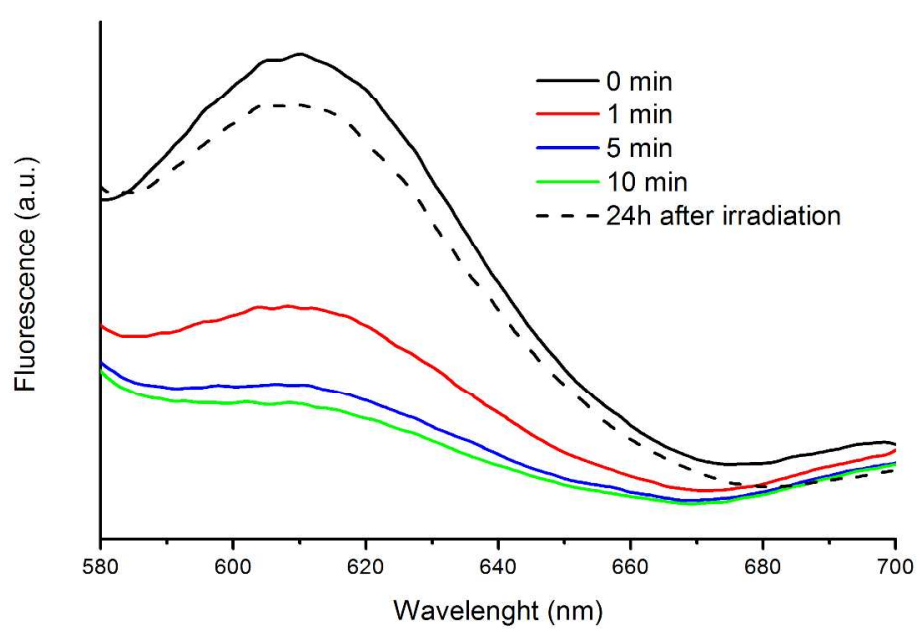

b)

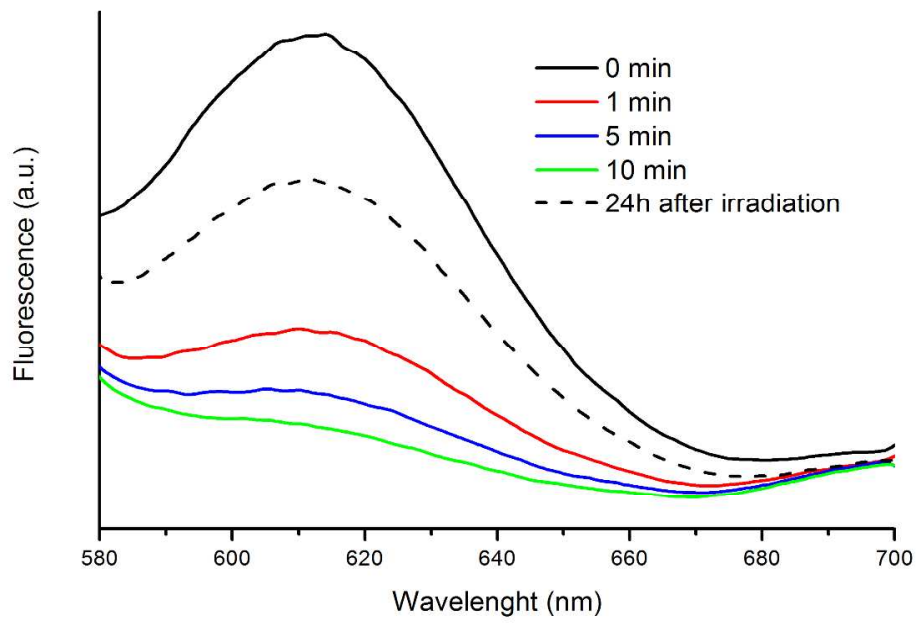


Figure 11. Emission spectra of the Nile Red encapsulated self-assemblies of (a) $\left\{\mathbf{P E G}_{\mathbf{2}}-\boldsymbol{b}\right.$ PDAP॰tAZO $\left.{ }_{i}\right\}$ and (b) $\left\{\right.$ PEG $\left._{10}-b-P D A P \bullet A Z Z O_{i}\right\}$, recorded after irradiation for different time intervals.
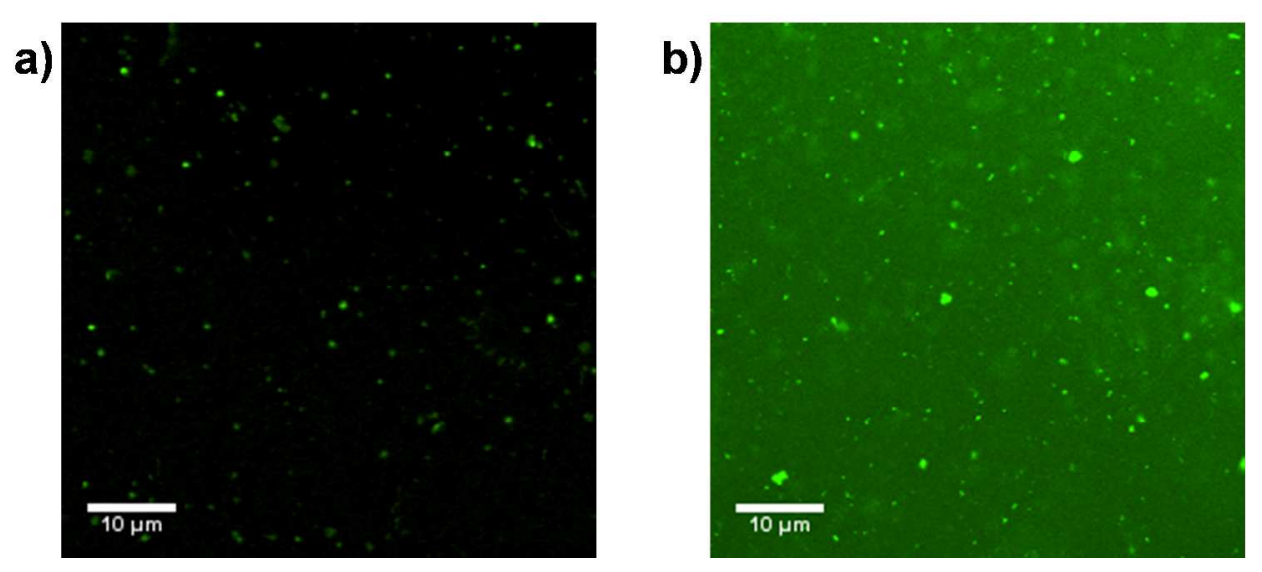

Figure 12. Fluorescence microscopy images of the water suspension of loaded $\left\{\mathbf{P E G}_{\mathbf{2}}-\boldsymbol{b}\right.$ -

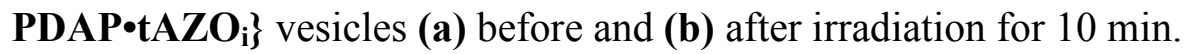

\section{CONCLUSIONS}

Supramolecular amphiphilic BCs based on the H-bond complexation of side chain 2,6diacylaminopyridine units with thymine functionalized 4-isobutyloxybenzene have been investigated as nanocarriers for capturing and light stimuli delivery of small molecules. These supramolecular BCs, in which PEG is used as the hydrophilic block, have been prepared by selectively embedding azobenzene units into the hydrophobic block through triple H-bonding. While for the parent BCs, $\mathbf{P E G}_{\mathbf{1 0}} \mathbf{- b}$-PDAP and $\mathbf{P E G}-\boldsymbol{b}$-PDAP, core-shell spherical micelles were formerly described, ${ }^{39}$ spherical micellar aggregates have been obtained for the 


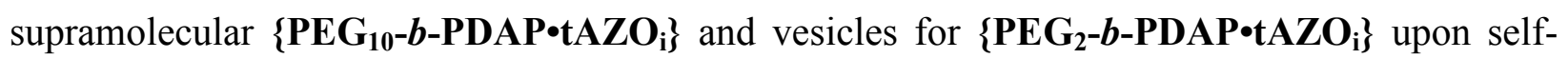
assembly in water.

Low intensity UV illumination of the self-assemblies in water triggered $E$-to- $Z$ isomerization of the azobenzene resulting in morphological changes that were observed by DLS and TEM, and were further confirmed by real time SAXS analyses. More concretely, TEM and SAXS provided evidence of distortion and thinning of the $\left\{\mathbf{P E G}_{\mathbf{2}}-\boldsymbol{b}-\mathbf{P D A P} \bullet \mathbf{t A Z O _ { i }}\right\}$ vesicles walls after UV exposure. These effects modify the permeability of the membrane towards guest molecules, either hydrophobic cargo molecules entrapped at the membrane, or hydrophilic ones entrapped at the internal aqueous cavity. On the other hand, light provokes the destruction of the core-shell PEG $_{10}-\boldsymbol{b}$-PDAP•tAZO $\}$ micelles, which endows in the release of hydrophobic molecules entrapped at the micellar hydrophobic core.

Finally, it should be highlighted that in general terms, the present supramolecular systems present similar light responsive capacities as those previously obtained for analogous covalent amphiphilic BCs. ${ }^{17,18,53,54}$ Thus it can be concluded that hydrogen bonding is an effective and flexible strategy to obtain stimuli responsive assemblies by avoiding the time-consuming procedures associated to the preparation of covalent amphiphilic BCs.

\section{ACKNOWLEDGEMENTS}

This work was supported by the MINECO, Spain, under the project MAT2014-59187-R and MAT2014-55205-P, FEDER funding and Aragón Government. A. Concellón acknowledges MINECO for his PhD grant. A. Martínez-Felipe thanks the financial support of the Generalitat Valenciana for his APOSTD/2013/054 grant. The authors would like to acknowledge the 
Servicio General de Apoyo a la Investigación - SAI and the Advanced Microscopy Laboratory LMA of the Universidad de Zaragoza and the Servei de Microscòpia of the Universitat Autònoma de Barcelona for the TEM and cryo-TEM observations. The authors additionally acknowledge the use of the CEQMA Services of the Universidad de Zaragoza-CSIC. The authors also thank the IACS (Aragón Health Sciences Institute) for the confocal microscope studies.

Supporting Information. Synthesis details and characterization of dAZOi and tAZOi. ${ }^{1} \mathrm{H}-{ }^{1} \mathrm{H}$

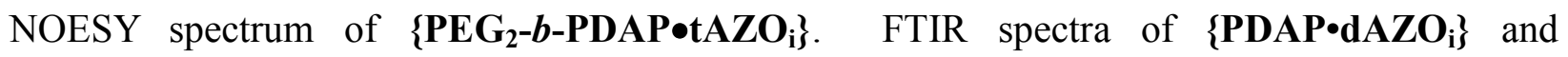
\{PDAP•tAZO $\}_{i}$. Self-Assembly of the supramolecular BCs in water and determination of CAC. This material is available free of charge via the Internet at http://pubs.acs.org. 
Table 1. Thermal parameters obtained for the azocompounds, parent polymers and supramolecular polymers

\begin{tabular}{|c|c|c|c|c|c|}
\hline & $\begin{array}{l}\text { Degree } \\
\text { complexation }^{\text {a }}\end{array}$ & $\begin{array}{l}\text { Hydrophilic/Hydrophobic } \\
\text { wt. ratio }{ }^{b}\end{array}$ & $T_{\text {onset }}{ }^{\mathrm{c}}\left({ }^{\mathrm{o}} \mathrm{C}\right)$ & $T_{\mathrm{g}}{ }^{\mathrm{d}}\left({ }^{\mathrm{o}} \mathrm{C}\right)$ & $T_{\mathrm{m}}{ }^{\mathrm{e}}\left({ }^{\mathrm{o}} \mathrm{C}\right)$ \\
\hline $\mathbf{t A Z O}_{\mathbf{i}}$ & - & - & 360 & - & 166 \\
\hline $\mathbf{d A Z O}$ & - & - & 350 & 68 & 141 \\
\hline PDAP & 0 & - & 255 & 73 & - \\
\hline $\mathbf{P E G}_{2}-\mathrm{CTA}$ & 0 & - & 210 & - & 48 \\
\hline PEG $_{2}-b$-PDAP & 0 & $35 / 65$ & 250 & 6 & - \\
\hline PEG $_{10}$-CTA & 0 & - & 310 & - & 58 \\
\hline PEG $_{10}-b-P D A P$ & 0 & $37 / 63$ & 255 & -3 & - \\
\hline$\left\{P D A P \bullet t A Z O_{i}\right\}$ & 1 & - & 265 & 35 & 148 \\
\hline$\left\{\mathrm{PEG}_{2}-b-\mathrm{PDAP} \bullet \mathrm{tAZO} \mathbf{O}_{\mathrm{i}}\right\}$ & 1 & $18 / 82$ & 250 & 33 & 40,140 \\
\hline$\left\{\mathrm{PEG}_{10}-b-\mathrm{PDAP} \bullet \mathrm{tAZO} \mathbf{i}_{\mathrm{i}}\right\}$ & 1 & $19 / 81$ & 270 & 38 & 48,146 \\
\hline 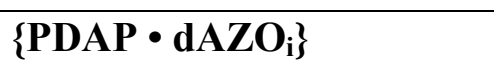 & 1 & - & 270 & 77 & 136 \\
\hline$\left\{\mathbf{P E G}_{\mathbf{2}}-\boldsymbol{b}-\mathrm{PDAP} \cdot \mathbf{d A Z O _ { i }}\right\}$ & 0.30 & $20 / 80$ & 255 & 4,80 & 40,139 \\
\hline$\left\{\mathrm{PEG}_{10}-b-\mathrm{PDAP} \bullet \mathrm{dAZO} \mathbf{i}_{\mathrm{i}}\right\}$ & 0.30 & $20 / 80$ & 265 & 15,79 & 52,140 \\
\hline
\end{tabular}

\footnotetext{
${ }^{a}$ Number of $\mathbf{t A Z O} \mathbf{O}_{\mathbf{i}}$ or $\mathbf{d A Z O} \mathbf{O}_{\mathbf{i}}$ molecules per 2,6-diacylaminopyridine repeating unit

${ }^{\mathrm{b}}$ Hydrophobic/hydrophilic ratio is given in weight percentage considering the PEG block as hydrophilic the PDAP

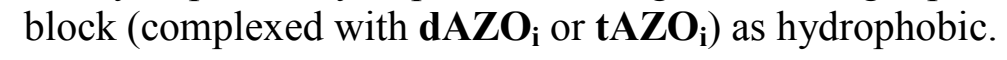


${ }^{\mathrm{c}}$ Onset temperature associated to mass loss detected in the thermogravimetric curve.

${ }^{\mathrm{d}}$ Glass transition temperature determined at the half height of the baseline jump on the second heating scan at 10 ${ }^{\circ} \mathrm{C} \cdot \mathrm{min}^{-1}$.

${ }^{\mathrm{e}}$ Melting temperature(s) read at the maximum of the peak on the second heating scan at $10^{\circ} \mathrm{C} \min ^{-1}$. 


\section{REFERENCES}

1. Riess, G. Micellization of block copolymers. Prog. Polym. Sci. 2003, 28, 1107-1170.

2. Letchford, K.; Burt, H. A review of the formation and classification of amphiphilic block copolymer nanoparticulate structures: micelles, nanospheres, nanocapsules and polymersomes. Eur. J. Pharm. Biopharm. 2007, 65, 259-269.

3. Smart, T.; Lomas, H.; Massignani, M.; Flores-Merino, M. V.; Perez, L. R.; Battaglia, G. Block copolymer nanostructures. Nano Today 2008, 3, 38-46.

4. Blanazs, A.; Armes, S. P.; Ryan, A. J. Self-assembled block copolymer aggregates: from micelles to vesicles and their biological applications. Macromol. Rapid Commun. 2009, 30, 267277.

5. Mai, Y.; Eisenberg, A. Self-assembly of block copolymers. Chem. Soc. Rev. 2012, 41, 5969-5985.

6. Onaca, O.; Enea, R.; Hughes, D. W.; Meier, W. Stimuli-responsive polymersomes as nanocarriers for drug and gene delivery. Macromol. Biosci. 2009, 9, 129-139.

7. Meng, F.; Zhong, Z.; Feijen, J. Stimuli-responsive polymersomes for programmed drug delivery. Biomacromolecules 2009, 10, 197-209.

8. Li, M.-H.; Keller, P. Stimuli-responsive polymer vesicles. Soft Matter 2009, 5, 927-937.

9. Zhao, Y. Photocontrollable block copolymer micelles: what can we control? J. Mater. Chem. 2009, 19, 4887-4895.

10. Fomina, N.; Sankaranarayanan, J.; Almutairi, A. Photochemical mechanisms of lighttriggered release from nanocarriers. Adv. Drug Deliv. Rev. 2012, 64, 1005-1020.

11. Gohy, J.-F.; Zhao, Y. Photo-responsive block copolymer micelles: design and behavior. Chem. Soc. Rev. 2013, 42, 7117-7129.

12. Blasco, E.; Piñol, M.; Oriol, L. Responsive linear-dendritic block copolymers. Macromol. Rapid Commun. 2014, 35, 1090-1115.

13. Wang, D.; Wang, X. Amphiphilic azo polymers: Molecular engineering, self-assembly and photoresponsive properties. Prog. Polym. Sci. 2013, 38, 271-301.

14. del Barrio, J.; Oriol, L.; Sanchez, C.; Luis Serrano, J.; Di Cicco, A.; Keller, P.; Li, M.-H. Self-assembly of linear-dendritic diblock copolymers: from nanofibers to polymersomes. J. Am. Chem. Soc. 2010, 132, 3762-3769. 
15. Lin, Y.-L.; Chang, H.-Y.; Sheng, Y.-J.; Tsao, H.-K. Photoresponsive polymersomes formed by amphiphilic linear-dendritic block copolymers: generation-dependent aggregation behavior. Macromolecules 2012, 45, 7143-7156.

16. Tong, X.; Wang, G.; Soldera, A.; Zhao, Y. How can azobenzene block copolymer vesicles be dissociated and reformed by light? J. Phys. Chem. B 2005, 109, 20281-20287.

17. Blasco, E.; del Barrio, J.; Sánchez-Somolinos, C.; Piñol, M.; Oriol, L. Light induced molecular release from vesicles based on amphiphilic linear-dendritic block copolymers. Polym. Chem. 2013, 4, 2246-2254.

18. Blasco, E.; Serrano, J. L.; Piñol, M.; Oriol, L. Light responsive vesicles based on lineardendritic block copolymers using azobenzene-aliphatic codendrons. Macromolecules 2013, 46, 5951-5960.

19. Dong, R.; Zhou, Y.; Huang, X.; Zhu, X.; Lu, Y.; Shen, J. Functional supramolecular polymers for biomedical applications. Adv. Mater. 2015, 27, 498-526.

20. Wang, D.; Tong, G.; Dong, R.; Zhou, Y.; Shen, J.; Zhu, X. Self-assembly of supramolecularly engineered polymers and their biomedical applications. Chem. Commun. 2014, 50, 11994-12017.

21. Kato, T.; Fréchet, J. M. J. Stabilization of a liquid-crystalline phase through noncovalent interaction with a polymer side-chain. Macromolecules 1989, 22, 3818-3819.

22. Fouquey, C.; Lehn, J. M.; Levelut, A. M. Molecular recognition directed self-assembly of supramolecular liquid crystalline polymers from complementary chiral components. Adv. Mater. 1990, 2, 254-257.

23. Brunsveld, L.; Folmer, B. J. B.; Meijer, E. W.; Sijbesma, R. P. Supramolecular polymers. Chem. Rev. 2001, 101, 4071-4097.

24. Lehn, J. M., Supramolecular polymer chemistry - scope and perspectives. In Supramolecular Polymers, Ciferri, A., Ed. Taylor \& Francis Group: 2005; pp 3-28.

25. Fox, J. D.; Rowan, S. J. Supramolecular polymerizations and main-chain supramolecular polymers. Macromolecules 2009, 42, 6823-6835.

26. Aida, T.; Meijer, E. W.; Stupp, S. I. Functional supramolecular polymers. Science 2012, $335,813-817$.

27. Zhang, Q.; Bazuin, C. G.; Barrett, C. J. Simple spacer-free dye-polyelectrolyte ionic complex: Side-chain liquid crystal order with high and stable photoinduced Birefringence. Chem. Mater. 2008, 20, 29-31. 
28. Marcos, M.; Alcalá, R.; Barberá, J.; Romero, P.; Sánchez, C.; Serrano, J. L. Photosensitive ionic nematic liquid crystalline complexes based on dendrimers and hyperbranched polymers and a cyanoazobenzene carboxylic acid. Chem. Mater. 2008, 20, 52095217.

29. Hernández-Ainsa, S.; Alcalá, R.; Barberá, J.; Marcos, M.; Sánchez, C.; Serrano, J. L. Ionic photoresponsive azo-codendrimer with room temperature mesomorphism and high photoinduced optical anisotropy. Macromolecules 2010, 43, 2660-2663.

30. Hernández-Ainsa, S.; Alcalá, R.; Barberá, J.; Marcos, M.; Sánchez, C.; Serrano, J. L. Ionic azo-codendrimers: influence of the acids contents in the liquid crystalline properties and the photoinduced optical anisotropy. Eur. Polym. J. 2011, 47, 311-318.

31. Priimagi, A.; Vapaavuori, J.; Rodríguez, F. J.; Faul, C. F. J.; Heino, M. T.; Ikkala, O.; Kauranen, M.; Kaivola, M. Hydrogen-bonded polymer-azobenzene complexes: enhanced photoinduced birefringence with high temporal stability through interplay of intermolecular interactions. Chem. Mater. 2008, 20, 6358-6363.

32. Vapaavuori, J.; Priimagi, A.; Kaivola, M. Photoinduced surface-relief gratings in films of supramolecular polymer-bisazobenzene complexes. J. Mater. Chem. 2010, 20, 5260-5264.

33. Vapaavuori, J.; Valtavirta, V.; Alasaarela, T.; Mamiya, J.-I.; Priimagi, A.; Shishido, A.; Kaivola, M. Efficient surface structuring and photoalignment of supramolecular polymerazobenzene complexes through rational chromophore design. J. Mater. Chem. 2011, 21, 1543715441 .

34. Vapaavuori, J.; Mahimwalla, Z.; Chromik, R. R.; Kaivola, M.; Priimagi, A.; Barrett, C. J. Nanoindentation study of light-induced softening of supramolecular and covalently functionalized azo polymers. J. Mater. Chem. C 2013, 1, 2806-2810.

35. Koskela, J. E.; Vapaavuori, J.; Ras, R. H. A.; Priimagi, A. Light-driven surface patterning of supramolecular polymers with extremely low concentration of photoactive molecules. ACS Macro Lett. 2014, 3, 1196-1200.

36. del Barrio, J.; Blasco, E.; Oriol, L.; Alcalá, R.; Sánchez-Somolinos, C. Diblock copolymerazobenzene complexes through hydrogen bonding: self-assembly and stable photoinduced optical anisotropy. J. Polym. Sci. Part A: Polym. Chem. 2013, 51, 1716-1725.

37. del Barrio, J.; Blasco, E.; Toprakcioglu, C.; Koutsioubas, A.; Scherman, O. A.; Oriol, L.; Sánchez-Somolinos, C. Self-assembly and photoinduced optical anisotropy in dendronized supramolecular azopolymers. Macromolecules 2014, 47, 897-906. 
38. Concellón, A.; Blasco, E.; Piñol, M.; Oriol, L.; Díez, I.; Berges, C.; Sánchez-Somolinos, C.; Alcalá, R. Photoresponsive polymers and block copolymers by molecular recognition based on multiple hydrogen bonds. J. Polym. Sci. Part A: Polym. Chem. 2014, 52, 3173-3184.

39. Concellón, A.; Clavería-Gimeno, R.; Velázquez-Campoy, A.; Abián, O.; Piñol, M.; Oriol, L. Polymeric micelles from block copolymers containing 2,6-diacylaminopyridine units for encapsulation of hydrophobic drugs. $R S C A d v$. 2016, 6, 24066-24075.

40. Balta Calleja, F. J.; Vonk, C. G., X-ray scattering of synthetic polymers. Elsevier: Amsterdam, 1989; p XI, 317 p.

41. Ezquerra, T. A.; Garcia-Gutierrez, M. C.; Nogales, A.; Gómez, M. A., Applications of synchrotron light to scattering and diffraction in materials and life sciences. Springer-Verlag: Berlin, 2009; p 314 p.

42. Yuan, W.; Wang, J.; Li, L.; Zou, H.; Yuan, H.; Ren, J. Synthesis, self-assembly, and multi-stimuli responses of a supramolecular block copolymer. Macromol. Rapid Commun. 2014, 35, 1776-1781.

43. Deans, R.; Ilhan, F.; Rotello, V. M. Recognition-mediated unfolding of a self-assembled polymeric globule. Macromolecules 1999, 32, 4956-4960.

44. Ilhan, F.; Gray, M.; Rotello, V. M. Reversible side chain modification through noncovalent interactions. "Plug and play" polymers. Macromolecules 2001, 34, 2597-2601.

45. Beijer, F. H.; Sijbesma, R. P.; Vekemans, J. A. J. M.; Meijer, E. W.; Kooijman, H.; Spek, A. L. Hydrogen-bonded complexes of diaminopyridines and diaminotriazines: Opposite effect of acylation on complex stabilities. J. Org. Chem. 1996, 61, 6371-6380.

46. Kato, T.; Nakano, M.; Moteki, T.; Uryu, T.; Ujiie, S. Supramolecular liquid-crystalline side-chain polymers built through a molecular recognition process by double hydrogen bonds. Macromolecules 1995, 28, 8875-8876.

47. Rainbolt, E. A.; Washington, K. E.; Biewer, M. C.; Stefan, M. C. Recent developments in micellar drug carriers featuring substituted poly(e-caprolactone)s. Polym. Chem. 2015, 6, 23692381.

48. Pauw, B. R.; Pedersen, J. S.; Tardif, S.; Takata, M.; Iversen, B. B. Improvements and considerations for size distribution retrieval from small-angle scattering data by Monte Carlo methods. J. Appl. Crystallogr. 2013, 46, 365-371.

49. Bressler, I.; Pauw, B. R.; Thunemann, A. F. McSAS: software for the retrieval of model parameter distributions from scattering patterns. J. Appl. Crystallogr. 2015, 48, 962-969. 
50. Feigin, L. A.; Svergun, D. I., Structure analysis by small angle X-ray and neutron scattering. Plenum Press: New York, 1987.

51. Pedersen, J. S.; Gerstenberg, M. C. Scattering form factor of block copolymer micelles. Macromolecules 1996, 29, 1363-1365.

52. Pedersen, J. S. Form factors of block copolymer micelles with spherical, ellipsoidal and cylindrical cores. J. Appl. Crystallogr. 2000, 33, 637-640.

53. Blasco, E.; Schmidt, B. V. K. J.; Barner-Kowollik, C.; Piñol, M.; Oriol, L. Dual thermoand photo-responsive micelles based on miktoarm star polymers. Polym. Chem. 2013, 4, 45064514.

54. Blasco, E.; Schmidt, B. V. K. J.; Barner-Kowollik, C.; Piñol, M.; Oriol, L. A novel photoresponsive azobenzene-containing miktoarm star polymer: self-assembly and photoresponse properties. Macromolecules 2014, 47, 3693-3700. 
TABLE OF CONTENTS GRAPHIC
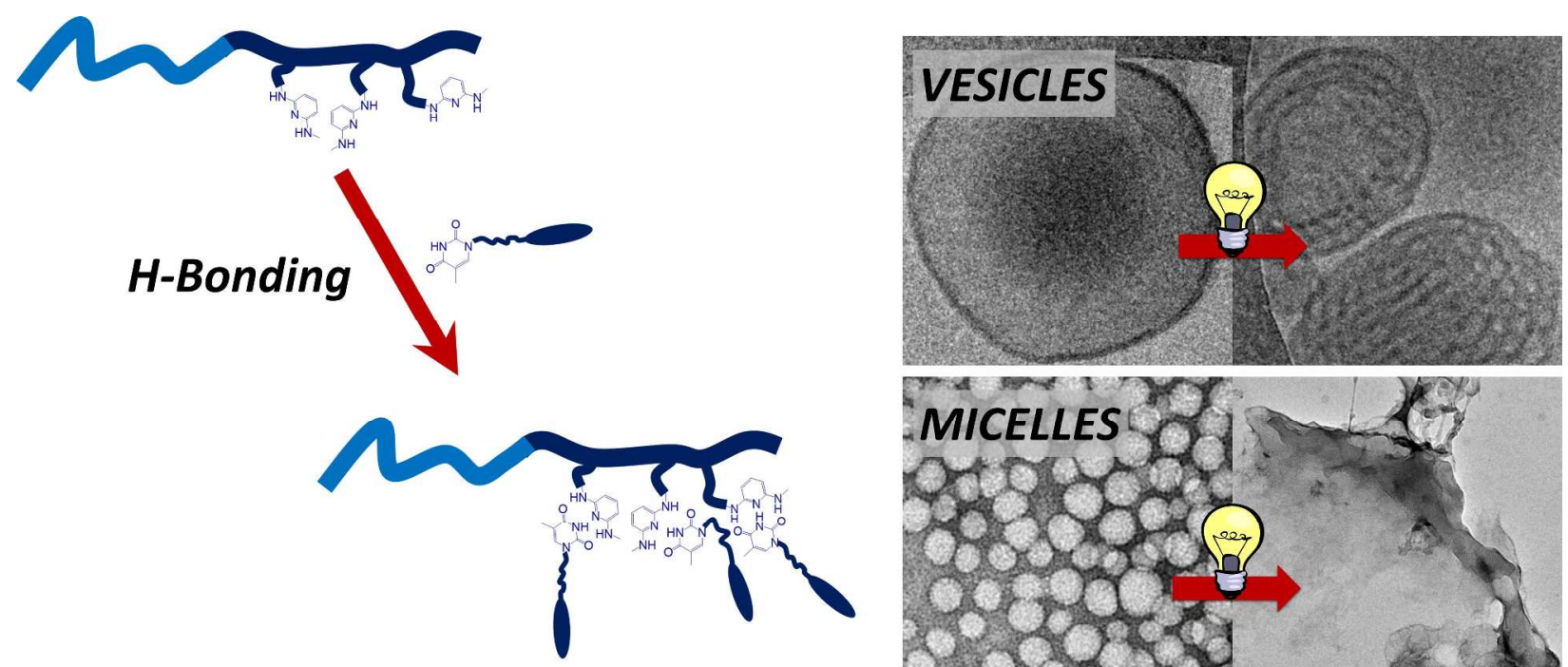

Supramolecular BC

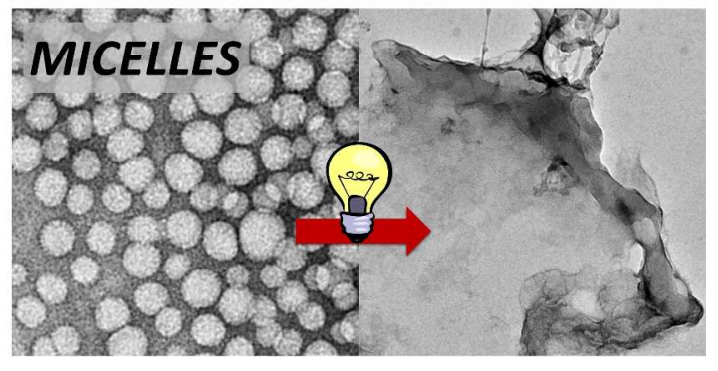

KEYWORDS

Amhiphilic block copolymers; suparamolecular post-functionalization; light-responsive nanoself-assemblies 